\title{
Vascular grafting strategies in coronary intervention
}

\author{
Darryl K. Knight ${ }^{1}$, Elizabeth R. Gillies ${ }^{1,2,3}$ and Kibret Mequanint ${ }^{1,2} *$ \\ 1 Department of Chemical and Biochemical Engineering, The University of Western Ontario, London, ON, Canada \\ ${ }^{2}$ Graduate Program in Biomedical Engineering, The University of Western Ontario, London, ON, Canada \\ ${ }^{3}$ Department of Chemistry, The University of Western Ontario, London, ON, Canada
}

\section{Edited by:}

Jian Yang, Pennsylvania State

University, USA

Reviewed by:

Deling Kong, Nankai University, China Antonio Webb, University of Florida,

USA

\section{*Correspondence:}

Kibret Mequanint, Department of Chemical and Biochemical

Engineering, The University of Western Ontario, 1151 Richmond

Street, London, ON N6A 5B9, Canada

e-mail:kmequani@uwo.ca
With the growing need for coronary revascularizations globally, several strategies to restore blood flow to the heart have been explored. Bypassing the atherosclerotic coronary arteries with autologous grafts, synthetic prostheses, and tissue-engineered vascular grafts continue to be evaluated in search of a readily available vascular graft with clinically acceptable outcomes. The development of such a vascular graft including tissue engineering approaches both in situ and in vitro is herein reviewed, facilitating a detailed comparison on the role of seeded cells in vascular graft patency.

Keywords: coronary artery bypass grafts, autologous grafts, synthetic prostheses, surface passivation, tissueengineered vascular grafts, acellular/decellularized scaffolds, cell sheet tissue engineering, cell seeding

\section{CLINICAL NEED FOR VASCULAR GRAFTS}

Of cardiovascular diseases, coronary artery disease (CAD) is the leading cause of death in the world, accounting for more than seven million deaths annually (Gaziano et al., 2010). The narrowing of the coronary arteries through the deposition of cholesterol, lipids, and calcium in a process known as atherosclerosis is the primary factor in coronary occlusion (Barron et al., 2003). With increased longevity, urbanization, and lifestyle changes in developing and transitional countries, the global burden of coronary heart disease will reach an estimated 82 million disability-adjusted life years (DALYs, or healthy years of life lost) by 2020 (Mackay et al., 2004), up from 58 million DALYs in 2001 (Gaziano et al., 2010).

In cases of advanced atherosclerosis where percutaneous coronary intervention (PCI) is deemed inappropriate for long-term revascularization, the more invasive coronary artery bypass graft (CABG) surgery is performed. Suitable bypass grafts are typically harvested from the patient themselves (autografts), but may also be obtained from a donor (allografts), a different species (xenografts), or obtained artificially (Barron et al., 2003).

\section{AUTOLOGOUS GRAFTS}

Natural vessel grafts, such as the greater saphenous vein, radial artery, and internal thoracic artery (ITA) have all been used as autologous bypass grafts (Dashwood and Tsui, 2013). The saphenous vein is frequently the conduit of choice due to its technical ease of use, or in cases of multiple grafting procedures or those patients undergoing repeat surgeries (Dashwood and Tsui, 2013). Despite the popularity of the saphenous vein bypass graft, it has shown limited long-term success with patency rates ranging from 57 to $61 \%$ at 10 years (Dashwood and Tsui, 2013) due to intimal and medial hyperplasia (Tatoulis et al., 2004; Sabik et al., 2005). Hyperplasia typically occurs at the anastomoses in large part due to the change in hemodynamic environment. The vein graft is now subject to increased pressures as well as shear and pulsatile forces associated with arterial blood flow, resulting in a phenotypic switch of the smooth muscle cells (SMCs) from the contractile to the synthetic phenotype (Shukla and Jeremy, 2012).

To improve the mechanical properties of arterial vein grafts and subsequently reduce hyperplasia, researchers have focused on reinforcing vein grafts with external support devices. Recently, cobaltchromium-nickel-molybdenum-iron alloy fibers were braided to form an expandable external support (Fluent, VGS-Vascular Graft Solution, Tel Aviv, Israel) for a vein graft in an ovine model. The authors observed a twofold decrease in neointimal hyperplasia from $23.1 \mathrm{~mm}^{2}$ in the control grafts vs. $11.2 \mathrm{~mm}^{2}$ in the supported grafts. The authors also noted that the graft's adventitia was incorporated into the device's pores, fixated by a thin layer of lucent connective tissue (Ben-Gal et al., 2013). Although an improvement in outcome and patency of the supported vein grafts was observed, the study was terminated at 3 months, which may have been insufficient to evaluate this medical device for the prevention of long-term occlusion due to hyperplasia.

External reinforcement around saphenous vein grafts has also been examined by Zilla and colleagues. In their studies, the authors devised a constrictive nitinol (nickel-titanium alloy) wire mesh to limit intimal hyperplasia by controlling the dilatation of the vein grafts, hence the shear stress, by constricting the diameter of the blood vessel while concomitantly reducing the wall stress of the native artery. The authors suggested that the reduction in shear stress due to the dilatation of the vein graft would induce intimal hyperplasia and that reducing the diameter of the vein graft would maintain the shear stress of the native artery. The authors reported that the vein graft that was constricted by $50 \%$ in a baboon model showed significantly suppressed intimal hyperplasia at both 6 and 12 weeks when compared to the unsupported vein grafts. Additionally, the authors demonstrated that only in the $50 \%$ constricted vein graft was endothelialization maintained (Zilla et al., 2008). Although the authors demonstrated some pulse compliance in a subsequent knitted nitinol wire mesh study, wire breakage and 
a lower degree of surface endothelialization was observed (Zilla et al., 2011).

Despite the decreased intimal hyperplasia observed with the supported vein grafts, the wire mesh supports are not biodegradable and thus, introduce the risk of future complications (Vijayan et al., 2004) should the wire supports fray, break, or undergo radial narrowing from axial distension (Zilla et al., 2008, 2011). Vijayan et al. examined a polyglactin biodegradable external sheath as support for porcine saphenous vein grafts to prevent future risks from permanent stents. The authors adopted a loose-fitting macroporous polyglactin stent for bilateral saphenous vein into common carotid artery interposition grafting in Large White pigs. At 1 and 6 months, the stented vein grafts showed decreased neointimal and medial thickening compared to unstented controls (Vijayan et al., 2004); however, the use of relatively small saphenous veins for interposition grafts in large arteries may have created flow conditions not clinically observed in bypass graft surgery (Zilla et al., 2008).

The radial artery is typically used as a free graft and has shown patency rates similar to or better than the saphenous vein (Hayward et al., 2010; Webb et al., 2010; Tranbaugh et al., 2012); however, risk for graft occlusion was higher in small target-vessel diameter cases (Desai et al., 2007). Moreover, elevated levels of vasoconstrictors including endothelin-1 and angiotensin II have been reported during and following the use of the radial artery in CABG surgery (He and Yang, 1997), necessitating pharmacological intervention (Chanda et al., 2000; Patel et al., 2012).

The ITA has provided greater long-term patency rates than the saphenous vein and radial artery due to its resistance to atherosclerosis (Shukla and Jeremy, 2012) and intimal hyperplasia (Sabik et al., 2005), and is now considered the conduit of choice for CABG surgery. Despite the increased patency rates resulting from ITA grafting, several issues remain. Use of the right ITA is limited due to its lack of proximity to major coronary arterial sites, rendering its use non-standardized (Bessone et al., 1995). Used as a free or composite graft, the right ITA has shown early graft occlusion, especially in cases of competitive flow (Kinoshita and Asai, 2011), mild to moderate stenosis (Pevni et al., 2007), and multiple anastomoses (Manabe et al., 2010).

\section{SYNTHETIC PROSTHESES}

Given that in CABG surgery, conduit availability, repeat operations, and graft failure are very real concerns of the autologous graft, synthetic materials as vascular grafts have been explored. Poly(ethylene terephthalate) $\left(\mathrm{PET}^{\circledR}, \mathrm{Dacron}\right)$, expanded poly(tetrafluoroethylene) (ePTFE, Gore-Tex ${ }^{\circledR}$ ), and heparinbonded ePTFE (Propaten ${ }^{\circledR}$ ) have demonstrated some degree of success as peripheral vascular grafts for larger vessel diameters due to high flow rates of blood past the luminal surface (Kapadia et al., 2008). In smaller diameter vessels (3-6 mm), early graft occlusion is frequently encountered, resulting from thrombogenicity of the synthetic surface and anastomotic hyperplasia (Chan-Park et al., 2009). Thrombus formation on the surface of a biomaterial is dictated by the Vroman effect of protein adsorption upon injury following implantation. Multiple factors including bloodmaterial interactions, the extent of cellular necrosis and inflammatory response, the loss of basement membrane structures, and subsequent provisional matrix formation are all contributing factors in the cascade of events of wound healing (Anderson, 2001). In effort to mitigate this cascade of events, much research has been focused on the passivation of the surface of vascular prostheses through the grafting of materials to reduce the electrostatic and hydrophobic interactions at the blood-biomaterial interface, and in particular to inhibit platelet adhesion and activation (Jordan and Chaikof, 2007). Natural and synthetic materials including poly(ethylene glycol) (PEG), dextran, pyrolytic carbon, phosphorylcholine (PC), albumin, and elastin-mimetic protein polymers have been investigated to minimize thermodynamically favored protein adsorption to the vascular graft surfaces (Jordan and Chaikof, 2007).

\section{VASCULAR PROSTHESES PASSIVATION}

Bureau and colleagues have recently examined non-woven PET fibers with surface-grafted PEG as potentially non-thrombogenic surfaces. The authors activated the surface of the PET with poly(vinyl amine) (PVAm), yielding pendant amine groups that were conjugated to carboxylic acid terminated PEG oligomers. The authors reported decreased platelet adhesion and activation with a $10 \%$ PEG solution grafting to the PVAm modified PET fibers when compared to knitted Dacron; however, the results were not superior to previously investigated carbon-coated ePTFE (Dimitrievska et al., 2011). In a prospective randomized multicenter study, Kapfer et al. demonstrated that in an extra-anatomical anterior tibial artery bypass model, carbon-impregnated ePTFE prostheses were not significantly better than standard ePTFE grafts in terms of graft patency or limb salvage (Kapfer et al., 2006). Similarly, Wang et al. also used PVAm to develop a surfactant polymer to coat ePTFE vascular grafts to prevent platelet adhesion and activation. The authors conjugated dextran to the PVAm backbone, which mimicked the polysaccharide-rich glycocalyx, generating a highly hydrated barrier, similar to the PEG-grafted PET fibers, inhibiting platelet adhesion and activation from both platelet-rich plasma and whole blood. Despite the promising in vitro results, the data from the proposed future study in a porcine model were never reported (Wang et al., 2009).

The highly hydrated surface of erythrocytes is also responsible for their non-thrombogenicity. The presence of the polar PC head groups of the lipid bilayer of the cell membrane are electrically neutral at physiologic $\mathrm{pH}$ while carrying both positive and negative charges. The zwitterionic nature of PC, resulting in the hydrated surface has shown limited protein and cell adhesion in vitro and thus has been explored as a non-thrombogenic coating on synthetic prostheses (Jordan and Chaikof, 2007). Yoneyama et al. demonstrated reduced thrombogenicity in an interpositional carotid rabbit model for up to 5 days with a segmented poly(etherurethane) (SPU)/2-methacryloyloxyethyl phosphorylcholine (MPC) polymer blend coating of Dacron prostheses (Yoneyama et al., 1998). Similarly, Chaikof and colleagues deposited a membrane-mimetic film onto the luminal surface of gelatin-impregnated ePTFE vascular prostheses and demonstrated reduced platelet adhesion after $1 \mathrm{~h}$ in a baboon femoral arteriovenous shunt model when compared to uncoated ePTFE grafts. The authors also observed a reduction in fibrinogen adhesion in the membrane-mimetic film coated graft; however, this 
reduction was not significant (Jordan et al., 2006; Jordan and Chaikof, 2007).

An alternative to the self-assembled phospholipid coating on MPC is the immobilization of merely the PC head group to the vascular prosthesis. Chevallier et al. functionalized the surface of ePTFE grafts through ammonia plasma treatment and then coupled PC to the resulting surface amino groups. The authors observed a concomitant decrease in platelet adsorption and activation and thrombogenicity index in the PC-functionalized grafts. Moreover, a significant reduction in neutrophil adhesion was observed, indicating a mitigation of the inflammatory response (Chevallier et al., 2005). In addition to the observed non-thrombogenicity of the PC, Chen et al. (1997) had previously demonstrated a reduction in neointimal hyperplasia with a PC coating of ePTFE grafts in a mongrel dog end-to-side carotid anastomoses model compared to virgin ePTFE grafts.

Instead of preventing platelet adhesion and activation through highly hydrophilic surfaces, some researchers have adopted the approach of controlled protein adsorption to inhibit coagulation. Albumin induces less platelet adsorption than other plasma proteins such as fibrinogen, which binds to the platelet GP IIb/IIIa receptor via arginine-glycine-aspartic acid (RGD) sequences (Zaidi et al., 1996; Jordan and Chaikof, 2007; Srokowski et al., 2011). Despite albumin's rapid adsorption to the surface of a synthetic material, more thermodynamically favored proteins replace albumin on the surface (Andrade and Hlady, 1987). Given the susceptibility of albumin to be displaced by larger proteins including fibrinogen, the promotion of albumin immobilization on the surface of vascular prostheses has been investigated. Choi et al. evaluated polylactide coated ePTFE grafts as a mediator of protein adsorption. The authors observed a preferential adsorption of albumin over fibrinogen on the surface of the coated ePTFE grafts compared to both unmodified and modified ePTFE grafts. The modified grafts were rendered more hydrophilic via chemical treatment, yielding an increase in surface energy. Despite the preferential adsorption of albumin, the polylactide surfaces induced greater blood cell adhesion than both control grafts suggesting a thrombogenic nature of the polylactide surface (Choi et al., 2005). In effort to mitigate the thrombogenicity of a secondary material, albumin was immobilized to the surface of knitted Dacron grafts through glutaraldehyde crosslinking. In this study, Kottke-Marchant et al. observed reduced platelet adhesion and aggregation, as well as reduced leukocyte adhesion with the crosslinked albumin-coated, knitted Dacron grafts when compared to unmodified Dacron. In addition, the release of fibrinopeptide $\mathrm{A}$, an indicator of fibrin formation, was also reduced in the albumin-coated knitted Dacron (Kottke-Marchant et al., 1989). Although promising in vitro, no difference was observed in clinical outcomes between the coated and uncoated grafts in arterial bypass grafts for aortoiliac disease (Bearn et al., 1993; Al-Khaffaf and Charlesworth, 1996).

Like albumin, elastin has also inhibited platelet aggregation (Baumgartner et al., 1976; Barnes and Maclntyre, 1979); however, the mechanism is not fully understood. Despite the initial studies of the antagonistic effect of elastin on platelet aggregation, few studies have evaluated the extracellular matrix (ECM) protein for passivation of vascular prostheses.
Woodhouse et al. have tested elastin-like peptides (ELPs) as coatings of vascular graft materials including PET $\left(\mathrm{Mylar}^{\mathrm{TM}}\right)$, poly(tetrafluoroethylene/ethylene) copolymer (Tefzel $\left.{ }^{\mathrm{TM}}\right)$, and a poly(carbonate urethane) (Corethane ${ }^{\mathrm{TM}}$ ). The authors passively coated all three test materials with a recombinant human elastin peptide and demonstrated a reduction in platelet activation in all cases. Moreover, fibrin accretion and thrombus formation on the surface of a polyurethane catheter was retarded in a New Zealand white rabbit model (Woodhouse et al., 2004). In a follow-up study, Woodhouse and colleagues reported platelet adhesion and fibrinogen adsorption on Mylar ${ }^{\mathrm{TM}}$ coated with three different ELPs. The authors observed a reduction in fibrinogen adsorption in all ELP-coated films; however, only the longer polypeptide chains exhibited decreased platelet adhesion (Srokowski et al., 2011). In a related study, an elastin-mimetic triblock protein polymer was evaluated by Chaikof and colleagues as a non-thrombogenic coating of impregnated ePTFE vascular grafts. They too observed inhibition of platelet adhesion and fibrin deposition in a baboon arteriovenous shunt model (Jordan et al., 2007). In addition to the non-thrombogenicity of ELPs and proteins, Ito et al. examined the effect of coacervated $\alpha$-elastin in preventing intimal hyperplasia. The authors observed a dose dependent decrease in smooth muscle cell proliferation in vitro with crosslinked coacervated $\alpha$-elastin, suggesting a potential reduction of intimal hyperplasia in vivo (Ito et al., 1998a). The authors repeated the study using tritiated thymidine to monitor cell proliferation and despite evidence suggesting that tritiated thymidine may result in cell arrest and apoptosis ( $\mathrm{Hu}$ et al., 2002), the authors reported increased endothelial cell proliferation at a coacervated $\alpha$-elastin concentration of $0.1 \mathrm{mg} / \mathrm{mL}$ (Ito et al., 1998b).

\section{BIOACTIVE VASCULAR PROSTHESES}

As active members of both anti-coagulant and anti-platelet mechanisms, endothelial cells (ECs) are integral in regulating hemostasis (Verhamme and Hoylaerts, 2006). Therefore, much research has been focused on mimicking the anti-thrombogenic features of the endothelial cell surface. Immobilization of anti-coagulant molecules thrombomodulin and heparin onto the surface of synthetic materials to directly inhibit thrombus formation has been studied. Mitigation of thrombus formation can be achieved through a number of coagulation or fibrinolytic pathways.

The surfaces of ePTFE prostheses have been modified to minimize pro-coagulation or anti-fibrinolytic mechanisms or conversely promote anti-coagulation and pro-fibrinolytic pathways. Thrombomodulin, an endothelial cell surface glycoprotein, strongly binds with thrombin forming a complex that inhibits the pro-coagulant properties of thrombin. Thrombomodulin also activates the anti-coagulant protease protein $\mathrm{C}$, which further hinders thrombus formation ( $\mathrm{Li}$ et al., 2000). Li et al. initially demonstrated that a soluble recombinant human thrombomodulin dose dependently retarded $\alpha$-thrombin-induced porcine arterial smooth muscle cell proliferation in vitro (Li et al., 2000). In a follow-up study, the authors demonstrated a reduction in neointimal hyperplasia in immobilized recombinant human thrombomodulin coated ePTFE stent grafts (Wong et al., 2008).

Heparin, a glycosaminoglycan that inhibits both thrombin and activated factors IX, X, XI, and XII, which are involved in the 
conversion of prothrombin to thrombin (Lin et al., 2004) has been extensively investigated. In addition to its anti-coagulation properties, heparin has been shown to reduce smooth muscle cell proliferation and thus possesses the capability to inhibit intimal hyperplasia (Clowes and Karnowsky, 1977). Lin et al. demonstrated the reduction in neointimal hyperplasia at both the proximal and distal anastomoses on heparin-coated ePTFE grafts in a baboon arteriovenous shunt model, as shown in Figure 1 (Lin et al., 2004). In a canine carotid artery interposition model, the end-point covalent attachment of heparin using the Carmeda ${ }^{\circledR}$ BioActive Surface (CBAS) technology to an expanded polytetrafluoroethylene graft compared favorably to a bare ePTFE graft. In a $2 \mathrm{~h}$ acute study, all five heparin-immobilized grafts remained patent exhibiting strong thromboresistance, while $60 \%$ of the control grafts occluded. In a longer-term study, 13 of 16 control grafts had occluded as early as 3 days, yet all CBAS-ePTFE remained patent. Following 180 days in the end-to-end anastomoses, seven CBAS-ePTFE grafts had occluded, while the three control grafts initially patent at 3 days remained patent or partially patent suggesting the heparin-immobilization reduced early graft thrombosis. Although, there was no statistical loss of heparin function at 12 weeks, the decreasing trend between weeks 2 and 12 suggests that at 180 days, the increase in occluded CBAS-ePTFE grafts may have resulted from a loss in heparin bioactivity (Begovac et al., 2003). In an ex vivo study, Heyligers et al. demonstrated a reduction in fibrinopeptide A on the heparin-immobilized grafts, suggesting an inhibition of fibrin deposition. Scanning electron microscopy revealed no platelet aggregation on the surface of the CBAS-ePTFE grafts confirming the thromboresistant nature of the heparinized ePTFE grafts (Heyligers et al., 2006). The promise that the heparin-bonded vascular graft could prevent early graft thrombosis through anti-coagulation and anti-platelet mechanisms led to its commercialization (Propaten ${ }^{\circledR}$ W. L. Gore \& Associates, Inc., Flagstaff, AZ, USA) and subsequent use as a peripheral vascular graft in humans.

In addition to being a part of the anti-coagulation and antiplatelet mechanisms, ECs also maintain hemostasis by providing a blood-compatible lining (Mason et al., 1977). In the absence of an adherent and coherent endothelium along the luminal surface of a synthetic graft, late stage thrombosis may still occur despite anti-coagulation therapy. Consequently, research has also focused on improving endothelial cell growth, retention, and confluency on the luminal surface of synthetic grafts. Due to electrostatic and hydrophobic interactions with ePTFE vascular grafts, incomplete endothelialization is typically encountered (Lu et al., 2013). Williams et al. have recently studied the effect of conjugated mouse laminin type 1 on endothelialization and neovascularization of ePTFE grafts as interpositional aortic grafts in rats. The presence of red cells, leukocytes, fibrin, and platelets in the control grafts suggested a highly thrombogenic surface, while the laminin type 1 conjugated grafts exhibited a complete lining of cells, indicative of an intact endothelium as shown in Figure 2. The authors also observed neovascularization in the interstices of the ePTFE grafts in the laminin-conjugated grafts (Williams et al., 2011).

Alternatively, Kibbe and colleagues mechanically coated the luminal nodes and fibrils of ePTFE with poly(1,8-octanediol citrate) (POC) and implanted the grafts in a porcine carotid model.

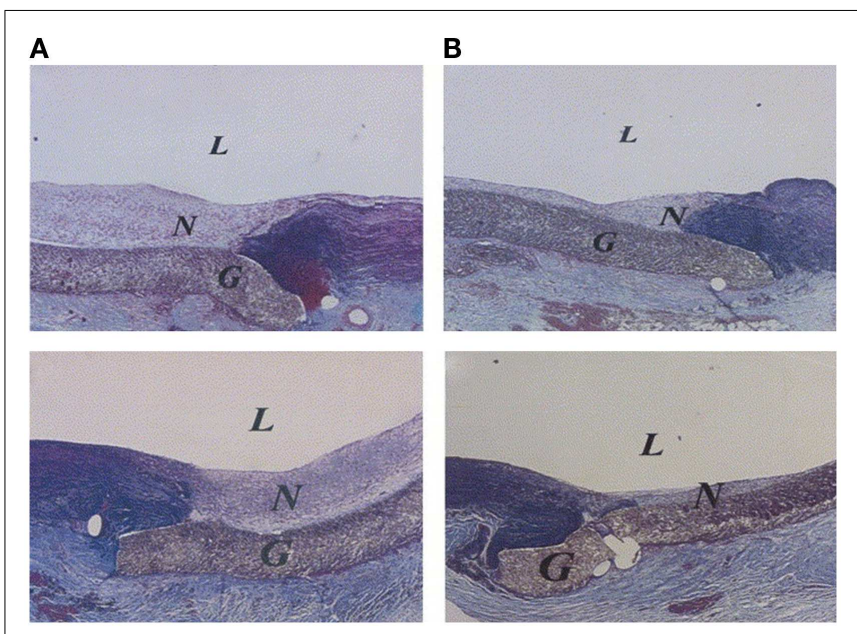

FIGURE 1 | Neointimal hyperplasia at proximal (top) and distal (bottom) anastomoses. Collagens are blue; elastin is black; others are red. (A) Anastomoses of untreated expandable poly(tetrafluoroethylene) (ePTFE) graft (control). (B) Anastomoses of heparin-coated ePTFE graft (treated). L, Lumen; N, neointima; G, ePTFE graft material

(Verhoeff-Masson stain; original magnification: 40x) (Lin et al., 2004).

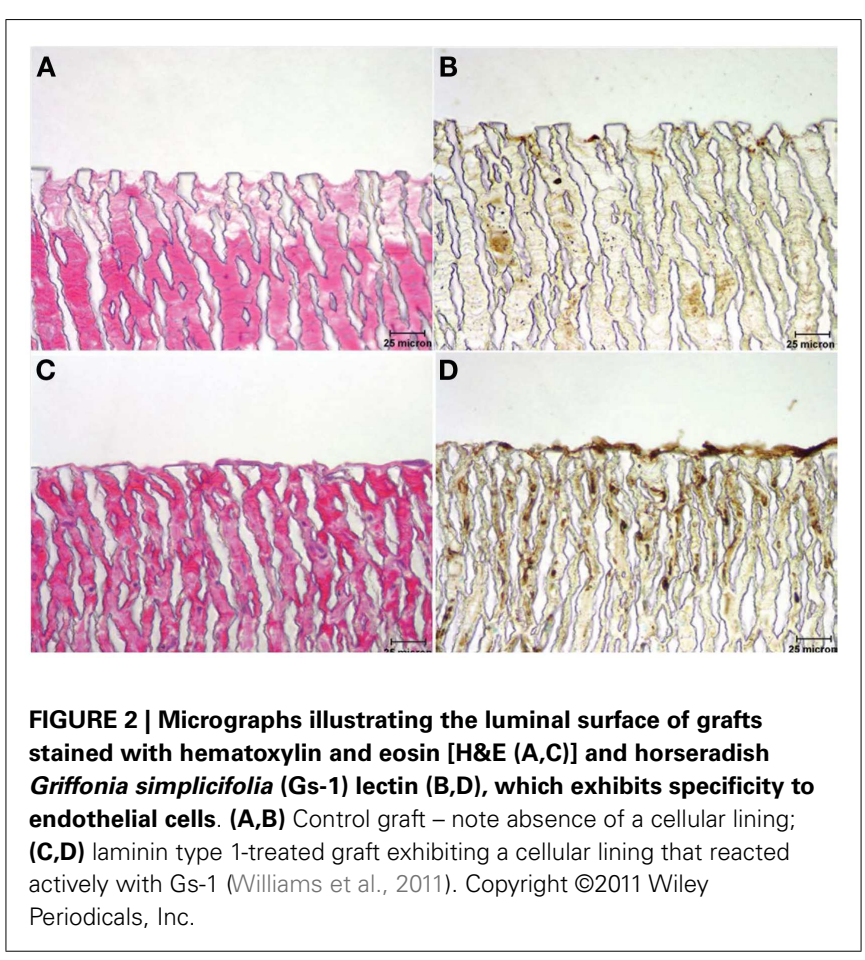

The authors demonstrated increased endothelial cell growth; however, confluency was only reached at 10 days. Moreover, the improved growth rate did not limit neointimal hyperplasia nor were the authors able to confirm that the neoendothelium was functional (Kibbe et al., 2010). Hoshi et al. took it a step further by covalently immobilizing heparin to the shear thinned POCcoated ePTFE vascular grafts. The authors demonstrated reduced 
whole blood clotting and platelet adhesion of the heparin immobilized POC-ePTFE grafts when compared to both POC-ePTFE and ePTFE grafts. In addition, the heparin conjugated grafts supported both endothelial cell and blood outgrowth endothelial cell adhesion as evidenced by expressions of von Willebrand factor ( $\mathrm{vWf}$ ) and vascular endothelial cadherin (Hoshi et al., 2013). The authors also claimed that SMCs cultured on the heparin-POC-ePTFE grafts showed increased expression of $\alpha$-actin and decreased cell proliferation, but the smooth muscle $\alpha$-actin (SM $\alpha \mathrm{A})$ expression was only examined qualitatively. The cell proliferation data showed that the heparin conjugated POC-ePTFE grafts resulted in a decreased SMC proliferation rate only when compared to twodimensional cell culture on tissue culture polystyrene (TCPS) and not when compared to POC-ePTFE grafts (Hoshi et al., 2013). Although this data does not suggest that intimal hyperplasia may be reduced due to decreased SMC with the heparin immobilized POC-coated ePTFE grafts, Hoshi et al. did demonstrate the combined benefit of anti-coagulant therapeutic delivery and improved endothelialization.

In a study by Lu et al., the authors coated $6 \mathrm{~mm}$ diameter ePTFE vascular grafts with an anti-CD133 antibody-functionalized heparin/collagen multilayer. Poly(ethyleneimine) (PEI) was electrostatically bound to the surface of the negatively charged ePTFE graft. Alternating immersion in heparin and collagen solutions generated a layer-by-layer self-assembled multilayered graft, which was then crosslinked with glutaraldehyde in the presence of antiCD133 to immobilize the antibody to the surface of the vascular graft. The authors chose to immobilize CD133 to the surface of the graft as CD133 is a cell surface antigen expressed on endothelial progenitor cells, which induced rapid endothelialization in a 7 day porcine carotid artery transplantation model. In addition to the in situ endothelialization, the authors reported significantly decreased platelet adhesion in the heparin/collagen coated ePTFE grafts. Despite the promise of the reported work, future studies will need to address two issues - appropriately sized ePTFE grafts $(<6 \mathrm{~mm})$ and longer in vivo studies to ensure no late stage thrombosis occurs due to a loss of functional endothelium (Lu et al., 2013).

Flameng and colleagues recently coated stem cell homing factor (SDF-1 $\alpha$ ) on the surface of Gelsoft ${ }^{\mathrm{TM}}$ (Vascutek Ltd., Inchinnan, Scotland) and Polymaille C (Pérouse Laboratories, Ivry le Temple, France), which are both knitted polyester vascular grafts precoated with collagen. The authors examined SDF- $1 \alpha$ as it acts as a chemoattractant for hematopoietic stem cells while inducing the recruitment of endothelial progenitor cells. The authors observed an increase in endothelialization from $27 \pm 4$ to $48 \pm 4 \%$ with the SDF- $1 \alpha$ coating compared to vascular grafts alone in an ovine model. Concurrently, they also observed a decrease in intimal hyperplasia (De Visscher et al., 2012).

\section{DEGRADABLE VASCULAR GRAFTS}

Although vascular prostheses are used effectively in large diameter vascular bypass graft surgery, particularly in the treatment of peripheral artery disease, there still remains no small-diameter vascular graft with clinically acceptable outcomes. In addition, the inability of these biostable vascular prostheses to undergo in vivo remodeling following implantation would preclude their use in pediatric cardiac patients who would need grafts to grow with them. Despite this lack of growth potential, the research applied to the passivation and endothelialization of vascular prostheses could be employed to vascular grafts that could undergo remodeling in vivo. For the vascular graft to integrate with the host's tissue, the graft itself must degrade following implantation, but in a manner adaptive to the needs of the host, ranging from pediatric to geriatric patients. Engineered degradable vascular grafts currently under investigation include both synthetic and biologically derived scaffolds, typically rendered biomimetic through functionalization and then potentially sodded with cells. These avenues of tissue engineering all seek to produce grafts promoting vascular cell migration and infiltration, presenting a non-thrombogenic luminal surface, and providing appropriate viscoelasticity and mechanical strength, especially during tissue regeneration.

\section{TISSUE ENGINEERING OF VASCULAR GRAFTS IN VIVO}

One approach in designing tissue-engineered vascular grafts (TEVGs) is through the implantation of an "off-the-shelf" acellular vascular scaffold. In vivo tissue engineering of vascular grafts necessitates the host's cells to infiltrate and populate a non-thrombogenic three-dimensional porous matrix, while concomitantly preventing blood leakage through the graft. As stated, the scaffold must also remain compliant to preserve the necessary hemodynamic environment, yet provide sufficient burst pressure and suture retention strengths. Given the extensive list of pre-requisites of a tissue-engineered vascular graft, numerous approaches have been adopted.

Walpoth and colleagues recently evaluated a bilayered biodegradable electrospun polycaprolactone (PCL) scaffold as a vascular graft. The authors prepared the bilayered PCL graft by electrospinning two different concentrations of PCL to obtain a nanofibrous luminal surface, and a microfibrous adventitial side (de Valence et al., 2012). The microfibrous matrix was designed to allow a dense infiltration of the SMCs, while the nanofibrous structure was designed to allow the ECs to bridge the gaps to form a confluent monolayer to prevent blood leakage. In a 4week bilateral porcine carotid artery model, the authors observed a marginal improvement in graft patency -78 versus $67 \%$ for the PCL and ePTFE vascular grafts, respectively. An increase in neoendothelialization from 58 to $86 \%$ was also observed in the PCL grafts. Despite the increase in endothelialization, neointima, and thrombus formation were not improved with the PCL electrospun vascular grafts (Mrówczyński et al., 2014). In a long-term followup study, the authors compared the patency of the bilayered PCL vascular graft against the ePTFE prosthesis in a Sprague-Dawley rat aorta replacement study. At a median of 16.5 months, the rats were euthanized, and the grafts were excised and examined. Graft patency in the PCL grafts was $100 \%$, while only $67 \%$ of ePTFE grafts remained patent. Although, there was a reduction in calcification and a concomitant improvement in cell infiltration and graft compliance with the PCL grafts when compared to ePTFE grafts, the PCL graft compliance was markedly less than the native aorta (Mugnai et al., 2013).

In a progressive study, Wang et al. (2014) examined the effect of PCL fiber diameter and pore size on arterial regeneration in a rat abdominal aorta model. All grafts remained patent through 
28 days, with one thicker-fiber $(5-6 \mu \mathrm{m})$ graft becoming occluded at 100 days ( $80 \%$ graft patency). Of all patent grafts, the luminal surface was smooth and free of platelets and thrombi, with a stable inner diameter suggesting no measurable restenosis. Moreover, significant cell infiltration was observed as early as 7 days in the thicker-fiber graft with both hematoxylin and eosin (H\&E) and $4^{\prime}, 6$-diamidino-2-phenylindole (DAPI) staining when compared to the thinner-fiber $(0.7 \mu \mathrm{m})$ graft. Of the infiltrating cells, $\mathrm{SM} \alpha \mathrm{A}$-positive cells were observed at 7 days around the connective tissue, but had migrated toward the luminal surface at 14 days. In addition, two of three explanted grafts exhibited a dense medial layer of smooth muscle myosin heavy chain (SMMHC)-positive cells at 28 days suggesting the generation of mature smooth muscle, which contracted in response to vasoconstrictors potassium chloride $(\mathrm{KCl})$ and adrenaline. Although complete endothelialization was not yet achieved at 28 days, $\mathrm{vWf}$ immunostaining revealed a coherent layer of ECs along the luminal surface of the graft at day 100, which underwent acetylcholine-induced relaxation following vasoconstriction. Given the functional smooth muscle and endothelium, histological staining with $\mathrm{H} \& \mathrm{E}$, Masson's trichrome, and Verhoeff-van Gieson (VVG) confirmed the initiation of vascular remodeling, as neotissue was observed in the lumen with ECM deposition within the graft. Although the elastin within the explanted graft did not exhibit the degree of undulation of the native aorta, the fibers were oriented circumferentially as part of as sub-endothelial layer. Despite the secretion of collagen and elastin, the circumferential strength of the explanted grafts mirrored that of the pre-implanted graft, while the magnitude of the contractile response of the explanted grafts were far less than the native aorta indicating little PCL matrix degradation (Wang et al., 2014). Given that arterial remodeling is expected to be slower in humans compared to rats (Swartz and Andreadis, 2013), the stiffer PCL (Young's modulus $\sim 21 \mathrm{MPa}$ ) vascular graft (Wang et al., 2014) could persist further mitigating vascular remodeling, while concomitantly limiting elastin synthesis (Crapo and Wang, 2010).

To further improve the interaction of PCL with both ECs and SMCs, recent work has focused on incorporating tripeptides to direct cell behavior. The cell adhesive motif RGD has been incorporated into a PCL-functionalized vascular graft. A naphthalene conjugated hexapeptide phenylalanine-phenylalanineglycine-arginine-glycine-aspartic acid (FFGRGD) self-assembled on the surface of the hydrophobic PCL yielding pendant RGD handles, which have previously been shown to provide improved hydrophilicity, cell attachment, and spreading. In an arteriovenous shunt model in female New Zealand White rabbits, Zheng et al. observed reduced platelet adhesion, improved patency, and smooth muscle cell infiltration and greater endothelialization with the RGD-functionalized PCL grafts. Although the authors reported improved smooth muscle cell infiltration and vasoactivity, this did not result in a thicker smooth muscle tissue, nor was endothelialization complete even after a 4-week implantation (Zheng et al., 2012). In a similar study, the tripeptide cysteinealanine-glycine (CAG) was electrospun with PCL fibers into a vascular graft and implanted in a Sprague-Dawley rat carotid artery model. Kuwabara et al. previously noted that the CAG tripeptide improved endothelialization, while it retarded smooth muscle cell proliferation. Upon excision at 1,2, and 4 weeks, the authors reported improved endothelialization at all time points and virtually complete endothelialization had occurred within 2 weeks. The presence of vWf was demonstrated at 1 week, while the production of endothelial nitric oxide synthase (eNOS) was detected as early as 1 week, demonstrating functional endothelium. The authors also demonstrated reduced $\mathrm{SM} \alpha \mathrm{A}$ expression at 6 weeks in the CAG-modified PCL graft, suggesting a potential to reduce intimal hyperplasia (Kuwabara et al., 2012); however, $\mathrm{SM} \alpha \mathrm{A}$ is a contractile phenotype marker protein and may not give a true representation of SMC proliferation.

Although these studies investigated the ability of PCL-modified vascular grafts to either improve patency, endothelialization, or SMC infiltration, only the study by Wang et al. fully examined neovascularization in vivo. Matsumura et al. had previously engineered a vascular graft consisting of polyglycolide knitted fibers and an L-lactide and $\varepsilon$-caprolactone copolymer sponge reinforced with glycolide and $\varepsilon$-caprolactone copolymer monofilaments, but only recently applied the biodegradable scaffold as a cell-free graft in a canine inferior vena cava (IVC) model. Immunohistological studies revealed endothelialization (factor VIII-positive) and SMC proliferation (SM $\alpha \mathrm{A})$ in the TEVG at 1 and 2.5 months with elastic and collagenous fibers also observed at 24 months. The authors reported no significant differences in the hydroxyproline, elastin, and calcium contents between the vascular graft and the native IVC up to 24 months follow-up. Moreover, the elastic modulus of the graft reached that of the native IVC at 2.5 months and continued to mirror the IVC up to 24 months following implantation (Matsumura et al., 2012). In a follow-up study, the authors examined their vascular graft in a canine pulmonary artery model. Again, they reported no significant differences in hydroxyproline and elastin content between the left pulmonary artery and the TEVG; however, significant calcification was observed with the TEVG at 12 months. Although the authors noted a lack of stenosis and thrombosis in the vasculature of any of the animals, the tubular scaffolds were $8 \mathrm{~mm}$ in diameter (Matsumura et al., 2013) and may not replicate the hemodynamics of a small-diameter blood vessel.

In another study examining neovascularization, Wang and colleagues implanted a poly(glycerol sebacate) (PGS) vascular graft supported with an outer PCL sheath in the abdominal aorta of Lewis rats. The sheath was electrospun around the tubular PGS graft to strengthen the graft, allowing it to be sutured in place, while preventing blood loss through the highly porous PGS network. The authors selected PGS because it is elastomeric, allowing for effective transduction of mechanical stimulation, while degrading rapidly in vivo, hence minimizing the host response to a foreign body. At 3 months, the authors observed significant SMC infiltration into the remodeled graft wall; however, $\mathrm{SM} \alpha \mathrm{A}$ expression was localized away from the luminal surface as shown in Figure 3 (Wu et al., 2012). The authors also demonstrated significant ECM production at 90 days. Verhoeff's, Masson's trichrome and safranin $\mathrm{O}$ staining revealed the presence of elastin, collagen, and glycosaminoglycans in the neoartery, nearing the ECM protein content of the native aorta, as shown in Figure 4 (Wu et al., 2012). The considerable ECM protein content also had a significant impact on the mechanical properties. The neoartery was tough yet compliant with a burst pressure approaching that of the 


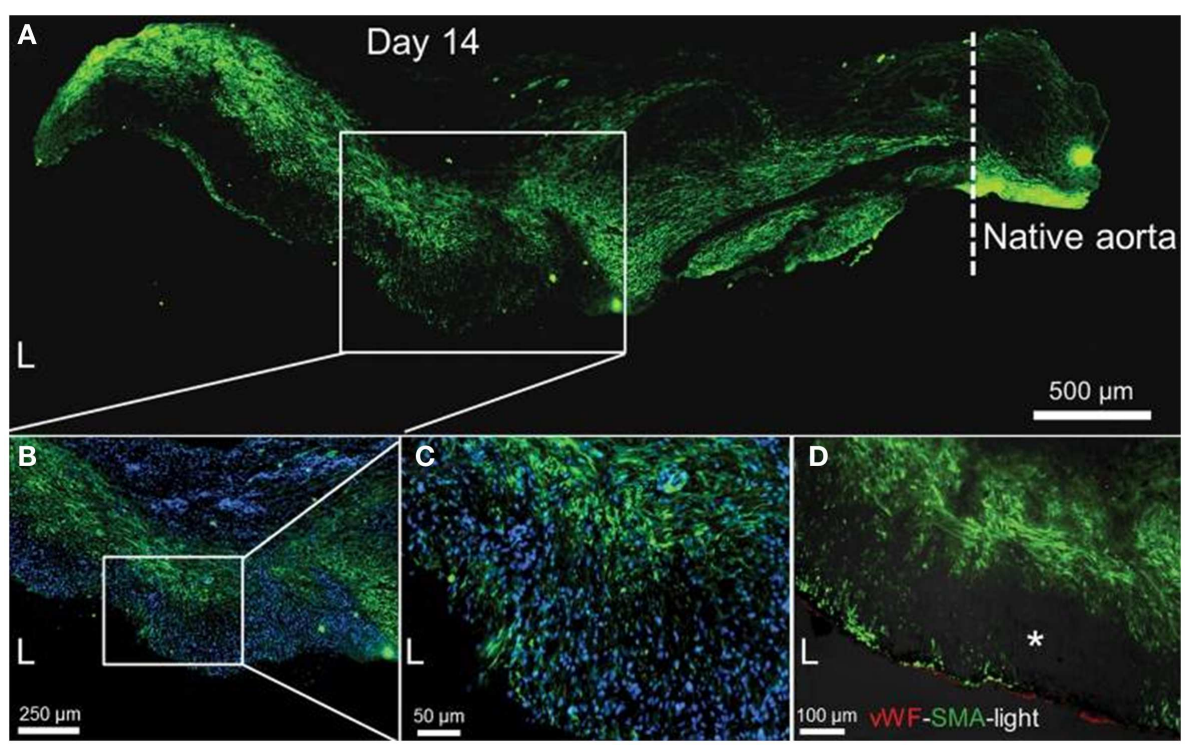

FIGURE 3 | Smooth muscle cell infiltration and organization at 14 days. (A) SMC distribution (SM $\alpha$ A, green) within the remodeled graft wall. The tissue was split longitudinally, half of which is shown. Native aorta is on the right; its border with the graft is indicated by the dashed line; scale bar, $500 \mu \mathrm{m}$. L, lumen. (B) Magnified view of the mid-graft shows distribution of both SM $\alpha$ A-positive (green) and SM $\alpha$ A-negative cells. Nuclei counterstained by DAPI (blue); scale bar, $250 \mu \mathrm{m}$. (C) Further magnification of the mid-graft to view the complicated SMC distribution (SM $\alpha$ A, green); scale bar, $50 \mu \mathrm{m}$. (D) Distribution of endothelial cells ( $\mathrm{WWf}$, red) and smooth muscle cells (SM $\alpha A$, green) in the graft wall. Immunofluorescence images merged with the bright-field image (darkened to not overwhelm the fluorescence images). Dark spots $\left(^{*}\right)$ in the bright-field image might be residual graft material; scale bar, $100 \mu \mathrm{m}$. Adapted by permission from Macmillan Publishers Ltd. [Nature Medicine] Mu et al., 2012), copyright (2012).

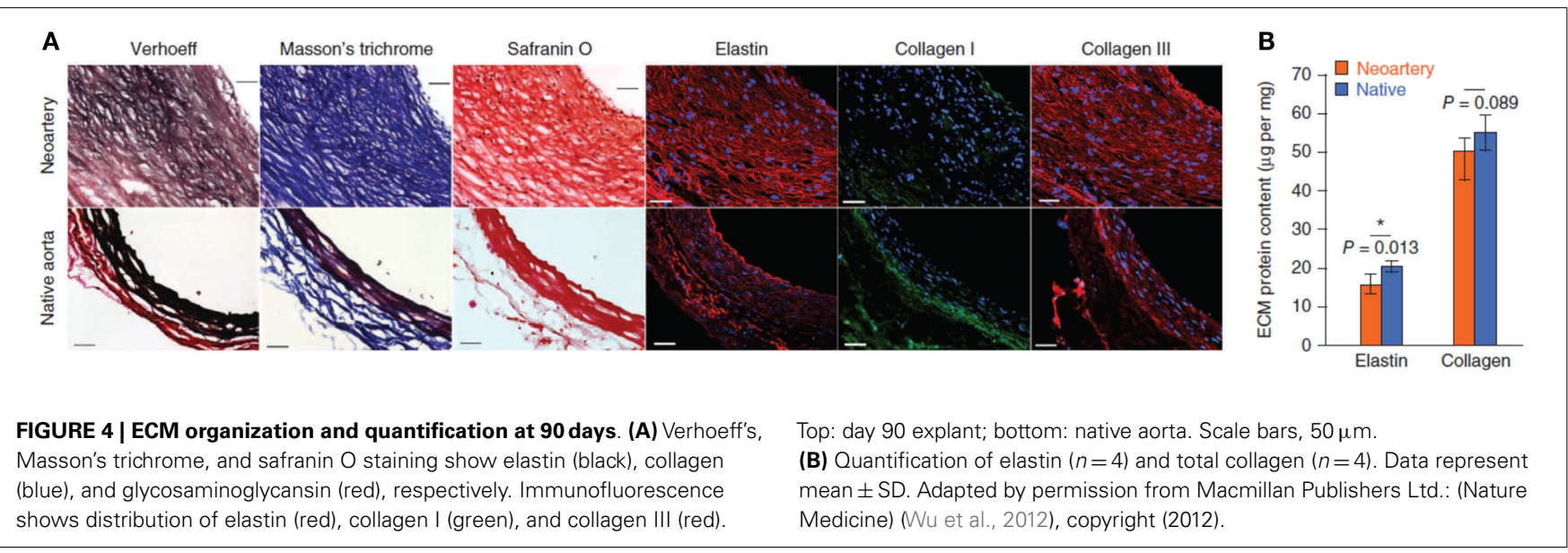

aorta and greater than the saphenous vein. Given the promising results, future studies with large animals more representative of the human vasculature are proposed.

Another material garnering attention as a vascular biomaterial is the elastomeric poly(ester urethane)urea (PEUU) derived from PCL diol, 1,4-diisocyanatobutane and putrescine in part due to its mechanical properties, as it has a burst pressure strength and suture retention strength approaching that of the ITA (Nieponice et al., 2008). Further to their original study, Vorp, Wagner, and colleagues have covalently attached MPC to the luminal surface of electrospun PEUU conduits to impart anti-thrombogenicity. The vascular grafts were then implanted in the abdominal aorta of rats and examined upon sacrifice at 4, 8, 12, and 24 weeks. The authors demonstrated a significant reduction in platelet adhesion in the PMA-conjugated PEUU grafts, with a corresponding patency rate of $92 \%$ compared to just $40 \%$ in the uncoated controls at 8 weeks. In the occluded grafts, $90 \%$ were attributed to acute thrombosis, while the remaining $10 \%$ failed due to intimal hyperplasia. The PMA-immobilized PEUU grafts also yielded aligned collagen and elastin fibers, both necessary precursors in neovascularization. Moreover, the authors also demonstrated an intact endothelium as evidenced by the continuity in vWf immunostaining between the native aorta and the electrospun PEUU graft. The authors also reported significant changes to the dynamic compliance and 
ultimate tensile strength of the functionalized PEUU grafts upon excision. An initial increase in the dynamic compliance and concomitant decrease in ultimate tensile strength was observed at 4 weeks and believed to be the result of acute degradation of the nodes of the electrospun fibers (Soletti et al., 2011).

Although the synthetic grafts may be easier to handle, suture, scale up, and sterilize, while yielding more reproducible properties, some researchers believe that the high modulus and tensile strength exhibited by fibroin, a component of spider silk, is equally viable as a vascular scaffold material. Catteneo et al. electrospun fibroin into $1.5 \mathrm{~mm}$ diameter tubular grafts that were implanted in the abdominal aorta of Lewis rats in end-to-end anastomoses. Upon explantation at 7 days, the constructs were infiltrated with SMCs and lined with ECs as evidenced by the immunostaining of $\mathrm{SM} \alpha \mathrm{A}$ and $\mathrm{vWf}$, respectively. The authors also reported the presence of elastin at 7 days, which by volume density, was approximately $50 \%$ of native vessels. Despite the evidence of complete endothelialization, the graft was only $1.5 \mathrm{~cm}$ in length (Cattaneo et al., 2013). In a similar study, Lovett et al. gel spun aqueous fibroin solutions to yield $2 \mathrm{~cm}$ silk tubular scaffolds and implanted them in the abdominal aorta of Sprague-Dawley rats. Silk fibroin (SF) grafts remained patent up to 4 weeks implantation, while acute thrombosis in all PTFE constructs was observed in $24 \mathrm{~h}$. The recruitment of vascular cells from the adjacent native aorta resulted in a medial smooth muscle layer and complete endothelialization as confirmed by $\mathrm{SM} \alpha \mathrm{A}$ and factor VIII staining. Further to the in vivo studies, the hemocompatibility of the SF grafts were also studied in vitro. A reduction in thrombin and fibrinogen adsorption was observed compared to PTFE and although an increase in platelet adhesion was seen from incubation of plateletrich plasma on SF films, the platelets were deemed non-activated by their non-spreading morphology (Lovett et al., 2010). In a complementary study, Yagi et al. prepared three kinds of knitted double-raschel silk fiber grafts coated with crosslinked SF again with an internal diameter of $1.5 \mathrm{~mm}$, but with a length of $7 \mathrm{~cm}$. The grafts were also implanted in the abdominal aorta of SpragueDawley rats. Upon excision at 8 weeks, gross observation of the vascular constructs revealed patency of the most elastic and flexible SF tubular graft tested, attributed to a reduction in intimal hyperplasia. Immunohistological studies revealed SMC infiltration, resulting in smooth muscle tissue thickness similar to that of the native rat aorta; however, complete endothelialization was not achieved, in particular at the midpoint of the vascular graft following 8 weeks implantation (Yagi et al., 2011). Given that incomplete endothelialization was observed, along with growing smooth muscle tissue, longer studies are necessary to ensure intimal hyperplasia does not result in occlusion of the vascular grafts.

Attempts to minimize intimal hyperplasia from SF scaffolds have been explored through the incorporation of heparin. Zhu et al. prepared heparin-loaded, porous scaffolds through a modified freeze-drying approach, which permitted their fabrication into tubular grafts. The authors demonstrated near complete release of heparin within 3 days corresponding to a reduction in SMC metabolic activity in vitro at 4 and 7 days. The ability of the SF scaffolds to facilitate tissue integration in vivo was evaluated upon excision of subcutaneously implanted tubular grafts in Sprague-Dawley rats. At 2 weeks, H\&E staining revealed initial tissue integration in the heparin-loaded grafts as evidenced by an increased number of capillaries; however, at 4 weeks, the number of capillaries decreased suggesting potential resorption of the de novo blood vessels. Although SMC metabolic activity was retarded at 4 and 7 days following the rapid release of heparin, there was no statistical difference in metabolic activity at 14 days (Zhu et al., 2014), suggesting a slower release profile or covalent attachment of heparin may be needed to prevent long-term intimal hyperplasia and ultimately graft occlusion.

Despite some promising results from foreign biomaterials, other researchers have proposed that clinical success will incorporate all fundamental features of the vascular wall. Kumar et al. have recently incorporated both fibrillar collagen type 1 and an elastinlike polypeptide as a vascular graft. Collagen fibrils were prepared from monomeric type 1 collagen extracted from rat tail tendon before the ELP was coated on the surface of the collagen and rolled to generate a luminal ELP layer on multiple fibrillar collagen layers. Initial studies revealed reduced platelet adhesion in the ELP-coated vascular graft when compared to the uncoated collagen graft control. Histologically, the 2-week rat aorta interposition study revealed little neointima formation, and continuous vWf staining indicative of an intact endothelium. Despite the promising short-term in vivo data, the burst pressure strength and suture retention strength still remain a fraction of that of the ITA (Kumar et al., 2013).

In effort to improve the mechanical properties of a vascular graft yet still incorporate the fundamental features of the vascular wall, research has focused on decellularized arterial conduits, which have demonstrated similar burst pressure strength, suture retention strength, and compliance to native blood vessels (Wilshaw et al., 2012; Sheridan et al., 2013; Xiong et al., 2013). Recently, Hwang et al. harvested abdominal aorta from SpragueDawley rats, which were evaluated as infrarenal allografts. The decellularized implants appeared thinner with the elastic fibers of the medial layer exhibiting less undulation when compared to the native aorta. Following 8 weeks implantation, intimal thickening due to increased collagen fibers and $\mathrm{SM} \alpha \mathrm{A}$-positive cells was observed. Although vWf staining revealed the presence of endothelial-like cells on the luminal surface of the implanted grafts, the expression was noticeably less than the native aorta (Hwang et al., 2011). In a related study, Akhyari and co-workers harvested rat aortae, which the authors decellularized and coated with fibronectin. The coated vessels were implanted systemically in Wistar rats for up to 8 weeks. Explanted fibronectin-coated grafts exhibited improved endothelialization and medial recellularization compared to uncoated controls. Despite the acceleration in endothelial cell recruitment, a concomitant increase in local hyperplasia was still observed (Assmann et al., 2013).

Similarly, Niklason and colleagues harvested human aortae and then decellularized the constructs to produce human tissueengineered vessels (hTEV). The decellularized hTEVs exhibited burst strength pressures similar to the saphenous vein, yet still inferior to the native ITA. The grafts were implanted in an end-to-end anastomoses in the abdominal aorta of female nude mice. Upon excision of the grafts at 6 weeks, there was evidence of neointima and neotissue formation on the decellularized grafts. Although cells did not fully infiltrate the decellularized graft, both elastin 
and SMCs were prevalent. In addition, vWf staining demonstrated the recruitment of ECs to the luminal surface of the vascular graft. The authors acknowledge that larger animal studies are needed and that these studies also need to examine the potential for late stage stenosis following neotissue or neointima formation (Quint et al., 2012).

\section{TISSUE ENGINEERING OF VASCULAR GRAFTS IN VITRO}

While some researchers have adopted the approach of in vivo tissue engineering, where cells are recruited into the biodegradable scaffold from adjacent tissue, others propose that seeded cells serve as the "building blocks of neotissue." In this regard, there are two unique approaches to enhance tissue regeneration and remodeling: cell sheet self-assembly and cell sodding of biodegradable scaffolds.

\section{Cell sheet tissue engineering}

The first tissue-engineered vascular graft (TEVG) prepared wholly from cultured human cells was developed by L'Heureux et al. (L'Heureux et al., 1993). Vascular SMCs obtained from umbilical veins and fibroblasts from human skin were cultured for 30 days with ascorbic acid to produce a cohesive cellular sheet with an associated ECM. The SMC layers were first peeled from the culture dish and enclosed around a tubular support to produce concentric sheet layers that mimic the media of the vessel. A secondary sheet of fibroblasts was then wrapped around the medial layers to emulate the adventitia. After an 8-week maturation period in a bioreactor, the perforated tubular mandrel was removed and luminal endothelial cell seeding was performed. The authors reported expression of vWf and strong inhibition of platelet adhesion in vitro from a coherent endothelium. The three-layered organization of the TEVG included both collagen and elastin, yielding a burst strength of over $2000 \mathrm{~mm} \mathrm{Hg}$, which is similar to that of human vessels. In a 7-day interpositional femoral artery graft in mongrel dogs, the authors reported patency in three of six animals, where occlusion from acute thrombosis resulted from non-endothelialized vascular grafts (L'Heureux et al., 1998). Subsequent in vivo studies evaluated the tissue-engineered blood vessels (TEBVs) longer-term, where the authors opted to implant the TEBV as interpositional abdominal grafts in immunodeficient rats. Of the patent grafts explanted between 3 and 8 months, grafttissue integration was reported along with a smooth endothelium with no observable change in the diameter of the graft. Moreover, $\mathrm{SM} \alpha \mathrm{A}$-positive cells infiltrated the media and were intertwined with collagen and elastin fibers. But to better mimic the biomechanical environment, the self-assembled TEBV was also applied as an interpositional arterial graft in immunosuppressed cynomolgus macaques. The explanted grafts were all patent ( $n=1$ at 6 weeks, $n=2$ at 8 weeks) and mirrored those previously excised from nude rats including having a smooth endothelium, $\mathrm{SM} \alpha \mathrm{A}$-positive cell recruitment, intact anastomoses with neither luminal narrowing nor aneurysm formation (L'Heureux et al., 2006).

Following the encouraging in vivo studies, L'Heureux and colleagues set out to assess the clinical relevance of TEBVs prepared from an age- and risk-appropriate patient population by comparing the burst pressure, suture retention strength, and compliance of the self-assembled engineered grafts to native blood vessels. The authors demonstrated similar burst pressure and suture retention strengths between the internal thoracic arteries and small-diameter TEBVs (2.4 $\mathrm{mm}$ diameter). Although initial compliance of the TEBVs is lower than the native ITA, at 6 months post-implantation, the compliance approached that of the native ITA due to the development of a functional smooth muscle cell media (Konig et al., 2009). Despite the promising results, vascular tissue maturation using the sheet-based technology requires at least 28 weeks, which would preclude it from urgent clinical use (L'Heureux et al., 2006; Konig et al., 2009).

Recent work using the cell sheet technology has focused on improved neovascularization through in vitro pre-vascularization. Okano and colleagues developed a five-layered construct where human umbilical vein endothelial cells (HUVECs) were seeded between myoblast sheets. Upon 4 days culture in vitro, capillarylike structures were partially formed and then implanted into dorsal subcutaneous tissue of nude rats. At 1 week post-implantation, the capillary-like structures joined the host's blood vessels creating microvessels, which also contained red blood cells (Sasagawa et al., 2010). In a more exhaustive study, Sekine et al. developed three-dimensional (3D) tissue with perfusable blood vessels in vitro. The authors isolated cardiac cells from the ventricles of Sprague-Dawley and Lewis neonatal rats (Sekine et al., 2013). Cardiac cells were co-cultured with ECs and seeded on temperature sensitive culture dishes for ease of cell sheet recovery. Upon stacking of the cardiac sheets, they were overlaid on a vascular bed from resected femoral tissue containing a connectable artery and vein as shown in Figure 5A. Media was supplied through the femoral artery (Figure 5B) and perfused through the vascular bed. The authors demonstrated that in the absence of ECs, no tubular structure was observed in the trilayered cell sheet, and that fibroblast growth factor-2 (FGF-2) was necessary to ensure media diffusion from the vascular bed to the cell sheet construct. In combination, the co-culture of ECs in the cardiac sheets enabled the formation of new blood vessels, while the FGF-2 facilitated the connection of these new blood vessels with the vasculature of the underlying femoral tissue. The three-dimensional tissueengineered construct remained viable in vitro via media supplied through the newly formed vessels. The functional tissue was then implanted in nude mice where the femoral artery and vein of the construct were reconnected to the carotid artery and the jugular vein, respectively. A cell sheet construct without a vascular bed and a vascular graft without blood vessel anastomoses served as controls. At 2 weeks, the rats were euthanized and tissue viability was significantly greater in the vascular graft with the blood vessel anastomoses. Moreover, immunostaining of CD31 and calponin highlighted a uniform distribution of blood vessels in the cell sheet construct (Sekine et al., 2013).

\section{Cell sodding of biodegradable scaffolds}

Weinberg and Bell were the first to prepare a biological vascular graft, which incorporated bovine SMCs, ECs, and fibroblasts into a collagen gel. The authors initially prepared the tunica media by embedding SMCs and culture media with collagen that gelled around a central mandrel within minutes at $37^{\circ} \mathrm{C}$. At 1 week, a Dacron mesh sleeve was placed over the collagen gel to provide additional mechanical support prior to the addition of adventitial 

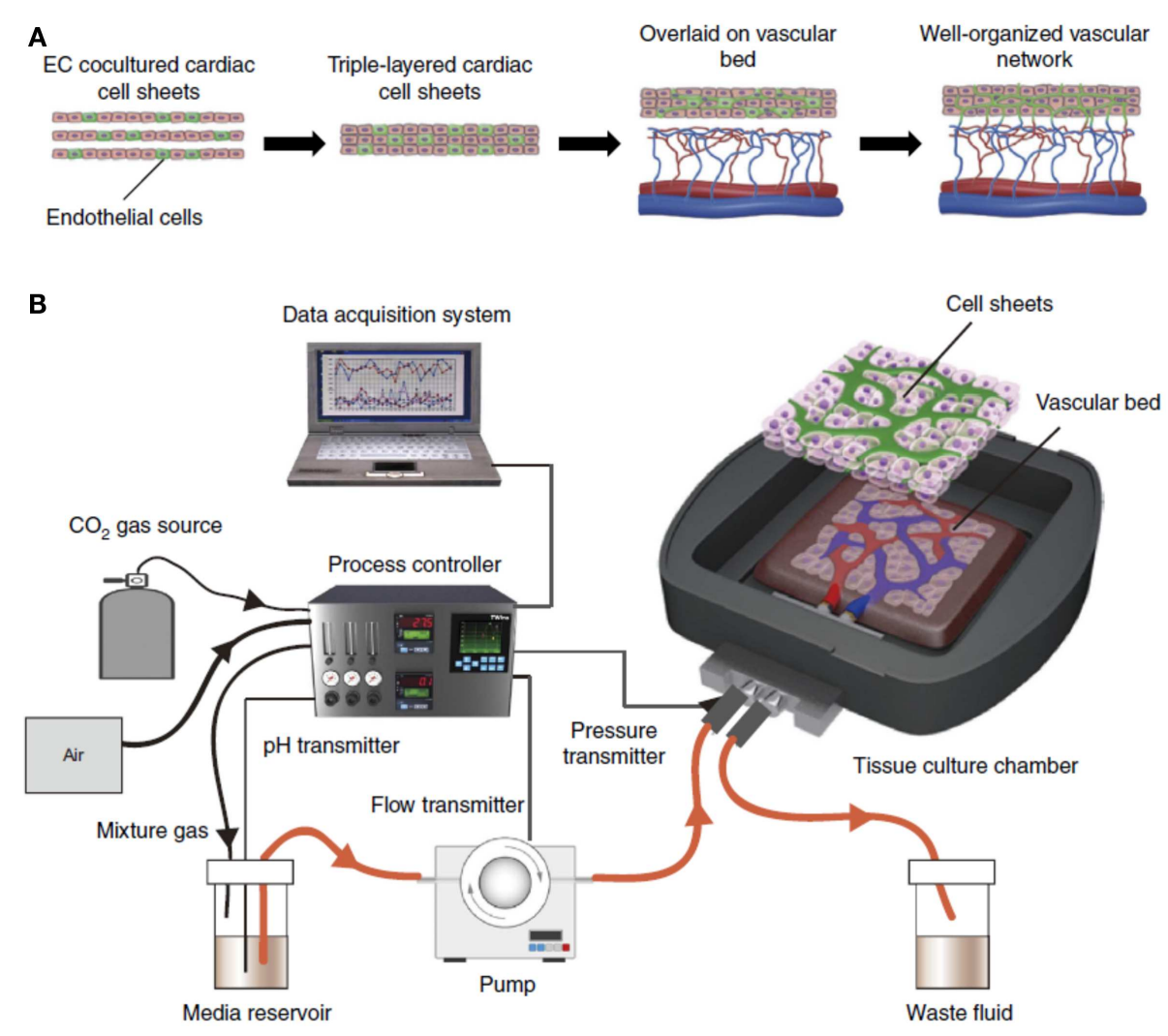

FIGURE 5 | In vitro engineering of functional 3D tissue with perfusable blood vessels. (A) To engineer cell sheet constructs with perfusable blood vessels, EC co-cultured cardiac cell sheets are stacked, and then overlaid on a vascular bed in vitro. After appropriate perfusion using a bioreactor, the co-cultured ECs formed new blood vessels and connected with the blood vessels that originated from the vascular bed. Finally, the cell sheet constructs survive via the media supplied through the new vessels formed in vitro. (B) The engineered constructs are perfused in a custom-made bioreactor. Adapted by permission from Macmillan Publishers Ltd.: (Nature Medicine) (Sekine et al., 2013), copyright (2013). fibroblasts. Upon removal of the mandrel, ECs were suspended in media and injected into the lumen of the vessel and rotated for a week to ensure uniform distribution. A virtually confluent monolayer of ECs produced vWf and prostacyclin, a known inhibitor of platelet aggregation. Despite the presence of a functional endothelium, burst strengths from the engineered vascular grafts could only be optimized to $323 \pm 31 \mathrm{~mm} \mathrm{Hg}$. The lack of burst strength was attributed to a number of factors including lack of elastin, low density of both SMCs and collagen as well as the longitudinal orientation of the collagen fibers and SMCs when compared to native blood vessels (Weinberg and Bell, 1986). Several attempts to improve the mechanical properties of collagen gels have been explored including crosslinking with glutaraldehyde, lysyl oxidase (Elbjeirami et al., 2003), and transglutaminase (Orban et al., 2004), yet no collagen construct approached the mechanical strength of native blood vessels.

Following the initial work with collagen gels, further efforts to improve the mechanical properties of cell sodded biodegradable scaffolds have been explored using bioreactors to replicate the cyclic hemodynamic loading experienced in vivo. Niklason et al. initially demonstrated that SMCs when cultured dynamically for 8 weeks on tubular degradable polyglycolic acid (PGA) meshes yielded densely packed layers of SMCs. The engineered vessels exhibited rupture strengths in excess of $2000 \mathrm{~mm} \mathrm{Hg}$ (Niklason et al., 1999), exceeding the burst pressure of the saphenous vein (L'Heureux et al., 1998). Subsequent studies have also revealed improved smooth muscle cell proliferation (Park et al., 2012) and mechanical properties in dynamic culture conditions (Wang et al., 2010; Song et al., 2011; Mun et al., 2013). In addition, the studies by Kim and colleagues revealed increased collagen (Mun et al., 2013) and elastin deposition under dynamic culture in their collagen coated poly(L-lactide-co- $\varepsilon$-caprolactone) tubular grafts; however, upon continued dynamic culture, loss of seeded HUVECs was observed (Park et al., 2012). Although dynamic culture of SMCs has demonstrated improved cell proliferation, ECM production, and cell orientation may be influenced by cell source, scaffold, and bioreactor design. Wang et al. demonstrated increased collagen deposition from adipose stem cell-derived SMCs in PGA meshes upon pulsatile flow, yet showed no effect on elastin synthesis (Wang et al., 2010). Three week dynamic cultures on elastomeric PGS tubular constructs resulted in increased levels of both insoluble collagen and elastin synthesis, which the authors attributed to improved mechanical transduction of the cyclic radial distension from the bioreactor to the SMCs (Lee and Wang, 2011). Kaplan and colleagues observed smooth muscle cell orientation parallel to fluid flow on silk-based scaffolds (Zhang et al., 2009), while 
both Lee and Wang and Ratcliffe reported smooth muscle cell orientation perpendicular to fluid flow on synthetic polymer based scaffolds, similar to native vessels (Lee and Wang, 2011; Ratcliffe, 2000). Despite the conflicting data, realizing that mechanical properties mimicking those of native blood vessels can be imparted to a tubular scaffold through the dynamic loading of a perfusion bioreactor facilitates the development of a tissue-engineered vascular graft.

Role of sodded cells. Although evidence of improved cell infiltration and orientation into vascular scaffolds during in vitro maturation further reinforced the adage that seeded cells served as the building blocks of neotissue, this behavior has not fully replicated in vivo. In 2008, Roh et al. developed a small $(<1 \mathrm{~mm})$ diameter vascular graft for use in a mouse model. The scaffolds were prepared by rolling non-woven polyester sheets of either PGA or poly(L-lactic acid) PLLA around either 21 or 22 gauge needles and then sealing them with a copolymer solution of poly ( $\varepsilon$-caprolactone-co-L-lactide) $[\mathrm{P}(\mathrm{CL} / \mathrm{LA})]$. The scaffolds had excellent mechanical properties with burst pressures in excess of the venous burst pressures and greater suture retention strength than both venous and arterial blood vessels. The intrinsic elasticity was measured as a function of Young's modulus, and despite the vascular scaffolds being stiffer than native vessels, the scaffolds were more elastic than ePTFE prosthetic grafts (Roh et al., 2008). In a follow-up study, the PGA-P(CL/LA) scaffolds were seeded with human bone marrow mononuclear cells (hBM-MNCs) and implanted as IVC interposition grafts in immunodeficient mice. The authors investigated the premise that stem cells in the BMMNC population differentiate into vascular SMCs and ECs of the neovessel. All hBM-MNC seeded vascular grafts remained patent throughout the 24 -week study. Upon study completion, mature vasculature was also evident including the presence of a confluent endothelium and a sub-endothelium SMC medial layer. Despite the degradation of the scaffold and its replacement with collagen fibrils, no elastin was detected in the TEVGs. Upon excision of the implants throughout the course of the 24week study, the authors tested the grafts for hBM-MNC surface antigens. After 1 week post-implantation, Roh et al. confirmed the absence of human RNA from the seeded hBM-MNCs in the TEVGs using quantitative real time polymerase chain reaction (qPCR). Although the hBM-MNCs were not retained or incorporated into the tissue-engineered vascular graft as differentiated cells, the presence of mouse SMCs and ECs following mouse monocyte recruitment suggested that the TEVGs appear to undergo inflammation-induced vascular remodeling. Despite the ultimate loss of hBM-MNCs, their secretion of the cytokine CCL2 increased monocyte recruitment suggesting that the hBM-MNCs were adopting a paracrine mechanism in neovessel development (Roh et al., 2010).

The postulation that seeded cells participate in neovessel formation via paracrine signaling was further evaluated. Breuer and his colleagues tested the effect of BM-MNCs on the TEVGs implanted in macrophage-depleted mice. The authors demonstrated that macrophages (differentiated monocytes) are critical for TEVG patency as the complete inhibition of macrophage infiltration prevented neotissue formation. Conversely, excessive macrophage infiltration was observed in the unseeded grafts, which resulted in neointimal hyperplasia, and ultimately a stenotic or occluded graft. In fact, early stenosis occurred in $80 \%$ of unseeded TEVGs, but only $20 \%$ of seeded TEVGs in an IVC interposition graft. Consequently, patency was improved in the cell-seeded grafts when compared to unseeded controls (Hibino et al., 2011b).

In spite of hBM-MNC loss upon implantation of the TEVG in immunodeficient mice, the patency of all grafts at 24 weeks with a well-developed vasculature including a coherent endothelium and smooth muscle cell medial layer suggested that the neovessel was composed entirely of host cells. To ensure that xenograft transplantation rejection was not responsible for the loss of hBMMNCs in the immunodeficient mice, syngeneic BM-MNCs were also seeded on TEVGs, and implanted in mice. Again the authors observed almost complete replacement of the BM-MNCs with macrophages, with only $0.02 \%$ of the originally seeded cells still present at 14 days. Moreover, the BM-MNCs were not a significant source of either the ECs or SMCs of the neovessel. The vascular cells forming $93 \%$ of proximal neotissue were in fact recruited from the adjacent vessel wall (Hibino et al., 2011a).

While seeded cells may not be incorporated into neotissue, extensive research demonstrates the improved patency of TEVGs seeded with cells. Mo and colleagues investigated preendothelialized vascular scaffolds in a canine bilateral femoral artery implant model. An autologous endothelial cell suspension was fed through tubular poly(L-lactic acid-co- $\varepsilon$-caprolactone) $[\mathrm{P}(\mathrm{LLA}-\mathrm{CL})]$ scaffolds and rotated on roller mixer for 7 days to ensure a uniform distribution of ECs prior to implantation. Graft patency was monitored using digital subtraction angiography and color Doppler flow imaging. As early as 1 week, three of eight P(LLA-CL) grafts had already occluded, and at 3 months, only one graft remained patent. Conversely, three of four preendothelialized grafts remained patent at 3 months, which the authors attributed to greater luminal monolayer coverage of the pre-seeded grafts (Huang et al., 2013). Notwithstanding the improved patency of the cell sodded grafts, the presence of a cell monolayer does not in and of itself prove that the seeded cells survived in the absence of a cell tracker. Although immunocytochemical analyses were not conducted, the presence of a cell monolayer and the patency of the vascular grafts suggest the TEVGs were lined with autologous ECs.

In addition to a functional endothelium, patent TEVGs will need to be supported with a medial layer of vasoactive SMCs; however, due to their slow propagation in vitro, focus has shifted to more rapidly proliferating stem cells or the incorporation of progenitor cells. Much controversy has surrounded the use of embryonic stem cells, but with the ability to harvest adult mesenchymal stem cells (MSCs) from bone marrow mononuclear cells, adipose tissue, and skeletal muscle tissue, significant research in stem cell-based tissue engineering has emerged (Krawiec and Vorp, 2012). In addition to the MSCs, the reprograming of somatic cells to induced pluripotent stem (iPS) cells has further expanded the possible use of stem cells in tissue engineering (Takahashi and Yamanaka, 2006).

Cho et al. were the first to examine differentiated bone marrow mononuclear cells in a TEVG in a canine carotid artery model. 
Both SM $\alpha$ A/SMMHC-positive cells and vWf/CD31-positive cells from the mononuclear cell fraction were cultured for 3 weeks in vitro to obtain enough cells for seeding. First, $\mathrm{SM} \alpha \mathrm{A} / \mathrm{SMMHC}-$ positive cells were uniformly seeded onto small-diameter decellularized canine carotid arteries, followed $2 \mathrm{~h}$ later by the vWf/CD31positive cells, which were seeded onto the luminal surface of the scaffolds and cultured for 1 week prior to implantation in an endto-end anastomoses of the carotid artery. Explanted grafts showed elements of an intact endothelium with well-defined medial and adventitial layers. Moreover, the TEVGs remained patent up to 8 weeks post-implantation, while unseeded grafts occluded within 2 weeks. The explanted grafts also revealed the presence of the fluorescently labeled BM-MNCs up to 8 weeks, indicating that some of the BM-MNCs actively participated in the vascular tissue regeneration (Cho et al., 2005). In a follow-up study, the authors seeded the canine BM-MNCs onto a poly(lactide-co- $\varepsilon$-caprolactone) scaffold supported by PGA fibers. Excision of the TEVGs at 8 weeks in a canine abdominal aorta model revealed that the TEVG underwent significant remodeling with a structure similar to that of the native aorta (Lim et al., 2008). Similarly, Zhou et al. decellularized a harvested canine carotid artery for examination as a TEVG. The decellularized vessel was coated with heparin, seeded with endothelial progenitor cells (EPCs) from peripheral blood, and matured in a bioreactor for 1 week prior to re-implantation. At 3 months, histological analyses revealed complete endothelialization in the EPC-seeded TEVG compared to unseeded decellularized vessels (DVs). In addition, immunofluorescence confirmed the presence of seeded cells lining the luminal surface of the TEVG. Significant reduction in hyperplastic neointima was also observed resulting in increased graft patency ( 95 versus $60 \%$ for the TEVGs and DVs, respectively) at 3 months (Zhou et al., 2012). The incorporation of the bone marrow mononuclear cells into the remodeled vascular tissue contradicts the observations of Breuer and colleagues; however, the behavior of MSCs is directly related to their perivascular environment (da Silva Meirelles et al., 2006) and may differ between humans and dogs.

Notwithstanding the in vivo remodeling following the TEVG implantation, the time needed for differentiation of the bone marrow mononuclear cells would hinder its use as an off-the-shelf vascular graft. The seeding of non-differentiated BM-MNCs onto a biodegradable vascular scaffold was first reported by Matsumura et al. The BM-MNCs were also seeded on a poly(lactide-co- $\varepsilon$ caprolactone) scaffold, but supported by poly(L-lactide) fibers and then implanted in the IVC of beagles. The explanted grafts were analyzed immunohistochemically at $3 \mathrm{~h}$ and again at 2, 4, and 8 weeks post-implantation. Stenosis was not observed in any of the TEVGs while patency was maintained up to 2 years following implantation. Immunohistochemistry revealed that seeded BM-MNCs initially expressed endothelial cell lineage markers including CD34, CD31, Flk-1, and Tie-2. Following proliferation and differentiation of the bone marrow mononuclear cells, expression of endothelial cell markers CD146, factor VIII, and CD31, as well as smooth muscle cell markers $\mathrm{SM} \alpha \mathrm{A}$, embryonic SMMHC (SMemb), and SMMHC isoforms SM1 and SM2 were observed implying the differentiation of the BM-MNCs into mature vascular cells in vivo (Matsumura et al., 2003). Despite the promising remodeling in vivo, the inner diameter of the degradable grafts selected for these studies were 10 and $8 \mathrm{~mm}$, respectively, approximately twice the diameter of any healthy male coronary artery (Dodge et al., 1992).

More recently Wu et al. compared four types of scaffolds (inner diameter of $5 \mathrm{~mm}$ ) to evaluate their ability to direct BM-MNC differentiation in vitro and promote vascular tissue formation. Rat BM-MNCs were seeded on PLGA, PGS, platelet-poor plasmacoated PGS, and plasma-coated PGS supplemented with platelets. The authors examined the impact of platelet adhesion on differentiation of bone marrow mononuclear cells, as platelets have been identified in recruiting circulating endothelial progenitor cells through paracrine release of stem cell-derived factor- $\alpha$ and vascular endothelial growth factor (VEGF). The expression of calponin-I and SM $\alpha \mathrm{A}$ and deposition of collagen and elastin from cells cultured on PGS scaffolds suggested smooth muscle differentiation. Although increased cell proliferation was observed with platelet supplementation, and hence ECM secretion, the authors did not report the impact of platelets on the differentiation of stem cells into mature ECs. vWf immunohistochemistry revealed the presence of the blood glycoprotein in platelets (Wu et al., 2011), but its absence at the luminal surface, as expected in ECs, perhaps suggests that the platelets did not actively recruit the EPCs from BM-MNCs, or that the BM-MNCs preferentially differentiated into SMCs.

Although, Wu et al. did not report the presence of ECs or their markers, bone marrow mesenchymal stems cells (MSCs), a small portion of the mononuclear cell fraction, have been successfully differentiated into ECs in vitro (Dong et al., 2009; Moby et al., 2011). The controlled in vitro differentiation of bone marrow MSCs to smooth muscle-like and endothelial-like cells can be achieved through supplement manipulation of the culture media (Zhao et al., 2010). Decellularized ovine carotid artery grafts were seeded with the autologous cells and implanted as interposition grafts. The seeded grafts remained patent for up to 5 months, while the unseeded controls occluded within 2 weeks. The presence of an endothelium and smooth muscle within the TEVG was observed at both 2 and 5 months as demonstrated through immunohistochemical staining of vWf and $\mathrm{SM} \alpha \mathrm{A}$, respectively. MSCs labeled with $\mathrm{PKH} 26$, a cell membrane bound fluorescent dye, was detected in the luminal side of the tunica media at 2 months, but not at 5 months, suggesting repopulation of the vascular graft (Zhao et al., 2010). Similar observations of improved patency have been reported with bone marrow MSC- and EPC-seeded PLLA-PGA scaffolds in a mouse carotid artery model. The authors also labeled the bone marrow MSCs with green fluorescent protein (GFP) and noted a reduction in GFP expression at 35 days when compared to 7 days, further supporting the premise of graft repopulation with host cells (Hjortnaes et al., 2010). Hashi et al. seeded bone marrow MSCs onto PLLA scaffolds and implanted them into the common carotid artery of rats for 60 days. Well-distributed SMCs within the TEVG indicated strong MSC infiltration and differentiation. Neointimal thickening was only observed in the unseeded controls. Staining for CD31 revealed not only luminal coverage of the TEVG with ECs, but their presence in the outer layer of the graft suggesting microvessel formation in the surrounding tissue. The authors also reported that explanted grafts at 60 days showed significant collagen deposition; however, only the MSC-seeded grafts 
exhibited a sub-luminal elastic lamina layer. Finally, the authors also showed that as early as 7 days, most cells were again recruited from the host due to the absence of human antigen nuclear mitotic apparatus staining in the seeded grafts (Hashi et al., 2007).

The accumulating evidence that cells sodded on vascular grafts significantly improve patency rates when compared to unseeded grafts, yet fail to integrate in neotissue formation, further validates the postulation that seeded cells supplement the host's innate healing process through paracrine signaling. Specifically, Breuer and colleagues believe that upon implantation of the bone marrow mononuclear cell-seeded tissue engineering graft, the BM-MNCs secrete chemokines such as CCL2, which is known to attract circulating monocytes. Following the differentiation of monocytes to macrophages, platelet derived growth factor (PDGF), and VEGF are released promoting infiltration of adjacent endothelial and SMCs, which together with the macrophages and fibroblasts begin secreting the ECM. During scaffold degradation, ECM remodeling continues with a concomitant exodus of macrophages yielding a completely autologous neovessel (Weber et al., 2011; Kurobe et al., 2012).

\section{CONCLUSION}

With the increasing rate of CAD coupled with the lack of autologous grafts due to repeat surgery or venous disease and the lack of growth potential in synthetic prostheses, the development of a tissue-engineered vascular graft remains an integral part of the coronary revascularization strategy. Although greater patency of TEVGs is being observed in animal models following cell sodding, the improved patency is attributed to paracrine signaling, suggesting the delivery of signaling molecules, potentially in lieu of a patient's own cells may facilitate the development of a readily available "off-the-shelf" vascular graft expediting its translation to the clinic.

\section{ACKNOWLEDGMENTS}

We thank the Natural Sciences and Engineering Research Council (NSERC) Discovery Grants (Elizabeth R. Gillies and Kibret Mequanint) and Postgraduate Scholarships Programs (Darryl K. Knight), the Canada Research Chairs Program (Elizabeth R. Gillies), and the Heart and Stroke Foundation Canada (Kibret Mequanint) for funding this work.

\section{REFERENCES}

Al-Khaffaf, H., and Charlesworth, D. (1996). Albumin-coated vascular prostheses: a five-year follow-up. J. Vasc. Surg. 23, 686-690. doi:10.1016/S0741-5214(96) 80050-4

Anderson, J. M. (2001). Biological responses to materials. Annu. Rev. Mater. Sci. 31, 81-110. doi:10.1146/annurev.matsci.31.1.81

Andrade, J. D., and Hlady, V. (1987). Plasma protein adsorption: the big twelve. Ann. N. Y. Acad. Sci. 516, 158-172. doi:10.1111/j.1749-6632.1987.tb33038.x

Assmann, A., Delfs, C., Munakata, H., Schiffer, F., Horstkötter, K., Huynh, K., et al. (2013). Acceleration of autologous in vivo recellularization of decellularized aortic conduits by fibronectin surface coating. Biomaterials 34, 6015-6026. doi:10.1016/j.biomaterials.2013.04.037

Barnes, M. J., and Maclntyre, D. E. (1979). Platelet-reactivity of isolated constituents of the blood vessel wall. Haemostasis 8, 158-170.

Barron, V., Lyons, E., Stenson-Cox, C., McHugh, P. E., and Pandit, A. (2003). Bioreactors for cardiovascular cell and tissue growth: a review. Ann. Biomed. Eng. 31, 1017-1030. doi:10.1114/1.1603260
Baumgartner, H. R., Muggli, R., Tschopp, T. B., and Turitto, V. T. (1976). Platelet adhesion, release and aggregation in flowing blood: effects of surface properties and platelet function. Thromb. Haemostasis 35, 124-138.

Bearn, P. E., McCoiium, C. N., and Greenhalgh, R. M. (1993). The influence of collagen and albumen presealants on knitted Dacron grafts. Eur. J. Vasc. Surg. 7, 271-276. doi:10.1016/S0950-821X(05)80008-8

Begovac, P. C., Thomson, R. C., Fisher, J. L., Hughson, A., and Gällhagen, A. (2003). Improvements in GORE-TEX ${ }^{\circledR}$ vascular graft performance by Carmeda ${ }^{\circledR}$ BioActive surface heparin immobilization. Eur. J. Vasc. Endovasc. Surg. 25, 432-437. doi:10.1053/ejvs.2002.1909

Ben-Gal, Y., Taggart, D., Williams, M., Orion, E., Uretzky, G., Shofti, R., et al. (2013). Expandable external support device to improve saphenous vein graft patency after CABG. J. Cardiothorac. Surg. 8, 122. doi:10.1186/1749-8090-8-122

Bessone, L. N., Pupello, D. F., Hiro, S. P., Lopez-Cuenca, E., Glatterer, M. S. Jr., Angell, W. W., et al. (1995). Sequential internal mammary artery grafting: a viable alternative in myocardial revascularization. Cardiovasc. Surg. 3, 155-162. doi:10.1016/0967-2109(95)90887-B

Cattaneo, I., Figliuzzi, M., Azzollini, N., Catto, V., Farè, S., Tanzi, M. C., et al. (2013). In vivo regeneration of elastic lamina on fibroin biodegradable vascular scaffold. Int. J. Artif. Organs 36, 166-174. doi:10.5301/IJAO.5000185

Chanda, J., Brichkov, I., and Canver, C. C. (2000). Prevention of radial artery graft vasospasm after coronary bypass. Ann. Thorac. Surg. 70, 2070-2074. doi:10.1016/S0003-4975(00)02001-4

Chan-Park, M. B., Shen, J. Y., Cao, Y., Xiong, Y., Liu, Y., Rayatpisheh, S., et al. (2009). Biomimetic control of vascular smooth muscle cell morphology and phenotype for functional tissue-engineered small-diameter blood vessels. J. Biomed. Mater. Res. A 88, 1104-1121. doi:10.1002/jbm.a.32318

Chen, C., Lumsden, A. B., Ofenloch, J. C., Noe, B., Campbell, E. J., Stratford, P. W., et al. (1997). Phosphorylcholine coating of ePTFE grafts reduces neointimal hyperplasia in canine model. Ann. Vasc. Surg. 11, 74-79. doi:10.1007/ s100169900013

Chevallier, P., Janvier, R., Mantovani, D., and Laroche, G. (2005). In vitro biological performances of phosphorylcholine-grafted ePTFE prostheses through RFGD plasma techniques. Macromol. Biosci. 5, 829-839. doi:10.1002/ mabi.200500088

Cho, S. W., Lim, S. H., Kim, I. K., Hong, Y. S., Kim, S. S., Yoo, K. J., et al. (2005). Small-diameter blood vessels engineered with bone marrow-derived cells. Ann. Surg. 241, 506-515. doi:10.1097/01.sla.0000154268.12239.ed

Choi, Y. J., Choung, S. K., Hong, C. M., Shin, I. S., Park, S. N., Hong, S. H., et al. (2005). Evaluations of blood compatibility via protein adsorption treatment of the vascular scaffold surfaces fabricated with polylactide and surface-modified expanded polytetrafluoroethylene for tissue engineering applications. J. Biomed. Mater. Res. A 75A, 824-831. doi:10.1002/jbm.a.30468

Clowes, A. W., and Karnowsky, M. J. (1977). Suppression by heparin of smooth muscle cell proliferation in injured arteries. Nature 265, 625-626. doi:10.1038/ 265625a0

Crapo, P. M., and Wang, Y. (2010). Physiologic compliance in engineered smalldiameter arterial constructs based on an elastomeric substrate. Biomaterials 31, 1626-1635. doi:10.1016/j.biomaterials.2009.11.035

da Silva Meirelles, L., Chagastelles, P. C., and Nardi, N. B. (2006). Mesenchymal stem cells reside in virtually all post-natal organs and tissues. J. Cell Sci. 119, 2204-2213. doi:10.1242/jcs.02932

Dashwood, M. R., and Tsui, J. C. (2013). 'No-touch' saphenous vein harvesting improves graft performance in patients undergoing coronary artery bypass surgery: a journey from bedside to bench. Vasc. Pharmacol. 58, 240-250. doi:10.1016/j.vph.2012.07.008

de Valence, S., Tille, J. C., Giliberto, J. P., Mrowczynski, W., Gurny, R., Walpoth, B. H., et al. (2012). Advantages of bilayered vascular grafts for surgical applicability and tissue regeneration. Acta Biomater. 8, 3914-3920. doi:10.1016/j.actbio.2012. 06.035

De Visscher, G., Mesure, L., Meuris, B., Ivanova, A., and Flameng, W. (2012). Improved endothelialization and reduced thrombosis by coating a synthetic vascular graft with fibronectin and stem cell homing factor SDF-1 $\alpha$. Acta Biomater. 8, 1330-1338. doi:10.1016/j.actbio.2011.09.016

Desai, N. D., Naylor, C. D., Kiss, A., Cohen, E. A., Feder-Elituv, R., Miwa, S., et al. (2007). Impact of patient and target-vessel characteristics on arterial and venous bypass graft patency: insight from a randomized trial. Circulation 115, 684-691. doi:10.1161/CIRCULATIONAHA.105.567495 
Dimitrievska, S., Maire, M., Diaz-Quijada, G. A., Robitaille, L., Ajji, A., Yahia, L., et al. (2011). Low thrombogenicity coating of nonwoven PET fiber structures for vascular grafts. Macromol. Biosci. 11, 493-502. doi:10.1002/mabi.201000390

Dodge, J. T. Jr., Brown, B. G., Bolson, E. L., and Dodge, H. T. (1992). Lumen diameter of normal human coronary arteries: influence of age, sex, anatomic variation, and left ventricular hypertrophy or dilation. Circulation 86, 232-246. doi:10.1161/01.CIR.86.1.232

Dong, J. D., Gu, Y. Q., Li, C. M., Wang, C. R., Feng, Z. G., Qiu, R. X., et al. (2009). Response of mesenchymal stem cells to shear stress in tissue-engineered vascular grafts. Acta Pharmacol. Sin. 30, 530-536. doi:10.1038/aps.2009.40

Elbjeirami, W. M., Yonter, E. O., Starcher, B. C., and West, J. L. (2003). Enhancing mechanical properties of tissue-engineered constructs via lysyl oxidase crosslinking activity. J. Biomed. Mater. Res. A 66, 513-521. doi:10.1002/jbm.a.10021

Gaziano, T. A., Bitton, A., Anand, S., Abrahams-Gessel, S., and Murphy, A. (2010). Growing epidemic of coronary heart disease in low- and middle-income countries. Curr. Probl. Cardiol. 35, 72-115. doi:10.1016/j.cpcardiol.2009.10.002

Hashi, C. K., Zhu, Y., Yang, G. Y., Young, W. L., Hsiao, B. S., Wang, K., et al. (2007). Antithrombogenic property of bone marrow mesenchymal stem cells in nanofibrous vascular grafts. Proc. Natl. Acad. Sci. U.S.A. 104, 11915-11920. doi:10.1073/pnas.0704581104

Hayward, P. A. R., Gordon, I. R., Hare, D. L., Matalanis, G., Horrigan, M. L., Rosalion, A., et al. (2010). Comparable patencies of the radial artery and right internal thoracic artery or saphenous vein beyond 5 years: results from the Radial Artery Patency and Clinical Outcomes trial. J. Thorac. Cardiovasc. Surg. 139, 60-67. doi:10.1016/j.jtcvs.2009.09.043

He, G. W., and Yang, C. Q. (1997). Radial artery has higher receptor-mediated contractility but similar endothelial function compared with mammary artery. Ann. Thorac. Surg. 63, 1346-1352. doi:10.1016/S0003-4975(97)00106-9

Heyligers, J. M. M., Verhagen, H. J. M., Rotmans, J. I., Weeterings, C., De Groot, P. G., Moll, F. L., et al. (2006). Heparin immobilization reduces thrombogenicity of small-caliber expanded polytetrafluoroethylene grafts. J. Vasc. Surg. 43, 587-591. doi:10.1016/j.jvs.2005.10.038

Hibino, N., Villalona, G., Pietris, N., Duncan, D. R., Schoffner, A., Roh, J. D., et al. (2011a). Tissue-engineered vascular grafts form neovessels that arise from regeneration of the adjacent blood vessel. FASEB J. 25, 2731-2739. doi:10.1096/fj.11-182246

Hibino, N., Yi, T., Duncan, D. R., Rathore, A., Dean, E., Naito, Y., et al. (2011b). A critical role for macrophages in neovessel formation and the development of stenosis in tissue-engineered vascular grafts. FASEB J. 25, 4253-4263. doi:10.1096/fj.11-186585

Hjortnaes, J., Gottlieb, D., Figueiredo, J. L., Melero-Martin, J., Kohler, R. H., Bischoff, J., et al. (2010). Intravital molecular imaging of small-diameter tissueengineered vascular grafts in mice: a feasibility study. Tissue Eng. C 16, 597-607. doi:10.1089/ten.TEC.2009.0466

Hoshi, R. A., Van Lith, R., Jen, M. C., Allen, J. B., Lapidos, K. A., and Ameer, G. (2013). The blood and vascular cell compatibility of heparin-modified ePTFE vascular grafts. Biomaterials 34, 30-41. doi:10.1016/j.biomaterials.2012.09.046

Hu, V. W., Black, G. E., Torres-Duarte, A., and Abramson, F. P. (2002). ${ }^{3}$ H-thymidine is a defective tool with which to measure rates of DNA synthesis. FASEB J. 16, 1456-1457. doi:10.1096/fj.02-0142fje

Huang, C., Wang, S., Qiu, L., Ke, Q., Zhai, W., and Mo, X. (2013). Heparin loading and pre-endothelialization in enhancing the patency rate of electrospun small-diameter vascular grafts in a canine model. ACS Appl. Mater. Interfaces 5, 2220-2226. doi:10.1021/am400099p

Hwang, S. J., Kim, S. W., Choo, S. J., Lee, B. W., Im, I., Yun, H. J., et al. (2011). The decellularized vascular allograft as an experimental platform for developing a biocompatible small-diameter graft conduit in a rat surgical model. Yonsei Med. J. 52, 227-233. doi:10.3349/ymj.2011.52.2.227

Ito, S., Ishimaru, S., and Wilson, S. E. (1998a). Application of coacervated $\alpha$-elastin to arterial prostheses for inhibition of anastomotic intimal hyperplasia. ASAIO J. 44, M501-M505. doi:10.1097/00002480-199809000-00036

Ito, S., Ishimaru, S., and Wilson, S. E. (1998b). Effect of coacervated $\alpha$-elastin on proliferation of vascular smooth muscle and endothelial cells. Angiology 49, 289-297. doi:10.1177/000331979804900407

Jordan, S. W., and Chaikof, E. L. (2007). Novel thromboresistant materials. J. Vasc. Surg. 45, 104-115. doi:10.1016/j.jvs.2007.02.048

Jordan, S. W., Faucher, K. M., Caves, J. M., Apkarian, R. P., Rele, S. S., Sun, X. L., et al. (2006). Fabrication of a phospholipid membrane-mimetic film on the luminal surface of an ePTFE vascular graft. Biomaterials 27, 3473-3481. doi:10.1016/j.biomaterials.2006.01.009

Jordan, S. W., Haller, C. A., Sallach, R. E., Apkarian, R. P., Hanson, S. R., and Chaikof, E. L. (2007). The effect of a recombinant elastin-mimetic coating of an ePTFE prosthesis on acute thrombogenicity in a baboon arteriovenous shunt. Biomaterials 28, 1191-1197. doi:10.1016/j.biomaterials.2006.09.048

Kapadia, M. R., Popowich, D. A., and Kibbe, M. R. (2008). Modified prosthetic vascular conduits. Circulation 117, 1873-1882. doi:10.1161/CIRCULATIONAHA. 107.714170

Kapfer, X., Meichelboeck, W., and Groegler, F. M. (2006). Comparison of carbonimpregnated and standard ePTFE prostheses in extra-anatomical anterior tibial artery bypass: a prospective randomized multicenter study. Eur. J. Vasc. Endovasc. Surg. 32, 155-168. doi:10.1016/j.ejvs.2005.12.015

Kibbe, M. R., Martinez, J., Popowich, D. A., Kapadia, M. R., Ahanchi, S. S., Aalami, O. O., et al. (2010). Citric acid-based elastomers provide a biocompatible interface for vascular grafts. J. Biomed. Mater. Res. A 93A, 314-324. doi:10.1002/jbm.a.32537

Kinoshita, T., and Asai, T. (2011). Bilateral internal thoracic artery grafting: current state of the art. Innovations (Phila) 6, 77-83. doi:10.1097/IMI. 0b013e3182166793

Konig, G., McAllister, T. N., Dusserre, N., Garrido, S. A., Iyican, C., Marini, A., et al. (2009). Mechanical properties of completely autologous human tissue engineered blood vessels compared to human saphenous vein and mammary artery. Biomaterials 30, 1542-1550. doi:10.1016/j.biomaterials.2008.11.011

Kottke-Marchant, K., Anderson, J. M., Umemura, Y., and Marchant, R. E. (1989). Effect of albumin coating on the in vitro blood compatibility of Dacron ${ }^{\circledR}$ arterial prostheses. Biomaterials 10, 147-155. doi:10.1016/0142-9612(89)90017-3

Krawiec, J. T., and Vorp, D. A. (2012). Adult stem cell-based tissue engineered blood vessels: a review. Biomaterials 33, 3388-3400. doi:10.1016/j.biomaterials.2012. 01.014

Kumar, V. A., Caves, J. M., Haller, C. A., Dai, E., Liu, L., Grainger, S., et al. (2013). Acellular vascular grafts generated from collagen and elastin analogs. Acta Biomater. 9, 8067-8074. doi:10.1016/j.actbio.2013.05.024

Kurobe, H., Maxfield, M. W., Breuer, C. K., and Shinoka, T. (2012). Concise review: tissue-engineered vascular grafts for cardiac surgery: past, present, and future. Stem Cells Trans. Med. 1, 566-571. doi:10.5966/sctm.2012-0044

Kuwabara, F., Narita, Y., Yamawaki-Ogata, A., Kanie, K., Kato, R., Satake, M., et al. (2012). Novel small-caliber vascular grafts with trimeric peptide for acceleration of endothelialization. Ann. Thorac. Surg. 93, 156-163. doi:10.1016/j.athoracsur. 2011.07.055

Lee, K. W., and Wang, Y. (2011). Elastomeric PGS scaffolds in arterial tissue engineering. J. Visual. Exp. 50:e2691. doi:10.3791/2691

L'Heureux, N., Dusserre, N., Konig, G., Victor, B., Keire, P., Wight, T. N., et al. (2006). Human tissue-engineered blood vessels for adult arterial revascularization. Nat. Med. 12, 361-365. doi:10.1038/nm1364

L'Heureux, N., Germain, L., Labbé, R., and Auger, F. A. (1993). In vitro construction of a human blood vessel from cultured vascular cells: a morphologic study. $J$. Vasc. Surg. 17, 499-509. doi:10.1067/mva.1993.38251

L'Heureux, N., Pâquet, S., Labbé, R., Germain, L., and Auger, F. A. (1998). A completely biological tissue-engineered human blood vessel. FASEB J. 12, 47-56.

Li, J., Garnette, C. S. C., Cahn, M., Claytor, R. B., Rohrer, M. J., Dobson, J G. Jr., et al. (2000). Recombinant thrombomodulin inhibits arterial smooth muscle cell proliferation induced by thrombin. J. Vasc. Surg. 32, 804-813. doi:10.1067/mva.2000.107992

Lim, S. H., Cho, S. W., Park, J. C., Jeon, O., Lim, J. M., Kim, S. S., et al. (2008). Tissue-engineered blood vessels with endothelial nitric oxide synthase activity. J. Biomed. Mater. Res. B 85B, 537-546. doi:10.1002/jbm.b.30977

Lin, P. H., Chen, C., Bush, R. L., Yao, Q., Lumsden, A. B., and Hanson, S. R. (2004). Small-caliber heparin-coated ePTFE grafts reduce platelet deposition and neointimal hyperplasia in a baboon model. J. Vasc. Surg. 39, 1322-1328. doi:10.1016/j.jvs.2004.01.046

Lovett, M., Eng, G., Kluge, J., Cannizzaro, C., Vunjak-Novakovic, G., and Kaplan, D. L. (2010). Tubular silk scaffolds for small diameter vascular grafts. Organogenesis 6, 217-224. doi:10.4161/org.6.4.13407

Lu, S., Zhang, P., Sun, X., Gong, F., Yang, S., Shen, L., et al. (2013). Synthetic ePTFE grafts coated with an anti-CD133 antibody-functionalized heparin/collagen multilayer with rapid in vivo endothelialization properties. ACS Appl. Mater. Interfaces 5, 7360-7369. doi:10.1021/am401706w 
Mackay, J., Mensah, G. A., Mendis, S., and Greenlund, K. (2004). “The burden,” in The Atlas of Heart Disease and Stroke, ed. H. Ann (Geneva: World Health Organization), 45-56.

Manabe, S., Fukui, T., Shimokawa, T., Tabata, M., Katayama, Y., Morita, S., et al. (2010). Increased graft occlusion or string sign in composite arterial grafting for mildly stenosed target vessels. Ann. Thorac. Surg. 89, 683-687. doi:10.1016/j. athoracsur.2009.11.053

Mason, R. G., Sharp, D., Chuang, H. Y., and Mohammad, S. F. (1977). The endothelium: roles in thrombosis and hemostasis. Arch. Pathol. Lab. Med. 101, 61-64.

Matsumura, G., Isayama, N., Matsuda, S., Taki, K., Sakamoto, Y., Ikada, Y., et al. (2013). Long-term results of cell-free biodegradable scaffolds for in situ tissue engineering of pulmonary artery in a canine model. Biomaterials 34, 6422-6428. doi:10.1016/j.biomaterials.2013.05.037

Matsumura, G., Miyagawa-Tomita, S., Shin'oka, T., Ikada, Y., and Kurosawa, H. (2003). First evidence that bone marrow cells contribute to the construction of tissue-engineered vascular autografts in vivo. Circulation 108, 1729-1734. doi:10.1161/01.CIR.0000092165.32213.61

Matsumura, G., Nitta, N., Matsuda, S., Sakamoto, Y., Isayama, N., Yamazaki, K., et al. (2012). Long-term results of cell-free biodegradable scaffolds for in situ tissue-engineering vasculature: in a canine inferior vena cava model. PLoS ONE 7:e35760. doi:10.1371/journal.pone.0035760

Moby, V., Labrude, P., Kadi, A., Bordenave, L., Stoltz, J. F., and Menu, P. (2011). Polyelectrolyte multilayer film and human mesenchymal stem cells: an attractive alternative in vascular engineering applications. J. Biomed. Mater. Res. A 96 A, 313-319. doi:10.1002/jbm.a.32981

Mrówczyński, W., Mugnai, D., de Valence, S., Tille, J. C., Khabiri, E., Cikirikcioglu, M., et al. (2014). Porcine carotid artery replacement with biodegradable electrospun poly- $\varepsilon$-caprolactone vascular prosthesis. J. Vasc. Surg. 59, 210-219. doi:10.1016/j.jvs.2013.03.004

Mugnai, D., Tille, J. C., Mrówczynski, W., de Valence, S., Montet, X., Möller, M., et al. (2013). Experimental noninferiority trial of synthetic small-caliber biodegradable versus stable vascular grafts. J. Thorac. Cardiovasc. Surg. 146, 400.e-407.e. doi:10.1016/j.jtcvs.2012.09.054

Mun, C. H., Jung, Y., Kim, S. H., Kim, H. C., and Kim, S. H. (2013). Effects of pulsatile bioreactor culture on vascular smooth muscle cells seeded on electrospun poly (lactide-co- $\varepsilon$-caprolactone) scaffold. Artif. Organs 37, E168-E178. doi:10.1111/aor.12108

Nieponice, A., Soletti, L., Guan, J., Deasy, B. M., Huard, J., Wagner, W. R., et al. (2008). Development of a tissue-engineered vascular graft combining a biodegradable scaffold, muscle-derived stem cells and a rotational vacuum seeding technique. Biomaterials 29, 825-833. doi:10.1016/j.biomaterials.2007.10.044

Niklason, L. E., Gao, J., Abbott, W. M., Hirschi, K. K., Houser, S., Marini, R., et al. (1999). Functional arteries grown in vitro. Science 284, 489-493. doi:10.1126/ science.284.5413.489

Orban, J. M., Wilson, L. B., Kofroth, J. A., El-Kurdi, M. S., Maul, T. M., and Vorp, D. A. (2004). Crosslinking of collagen gels by transglutaminase. J. Biomed. Mater. Res. A 68, 756-762. doi:10.1002/jbm.a.20110

Park, I. S., Kim, Y. H., Jung, Y., Kim, S. H., and Kim, S. H. (2012). A dynamically cultured collagen/cells-incorporated elastic scaffold for small-diameter vascular grafts. J. Biomater. Sci., Polym. Ed. 23, 1807-1820. doi:10.1163/ $156856211 \times 598201$

Patel, M., Meyer, T., Tharakan, A., and Tobias, J. D. (2012). Intraoperative administration of clevidipine to prevent vasospasm after radial and internal mammary artery grafts during coronary artery bypass grafting. Am. J. Ther. 19, e114-e117. doi:10.1097/MJT.0b013e3181e907b9

Pevni, D., Hertz, I., Medalion, B., Kramer, A., Paz, Y., Uretzky, G., et al. (2007). Angiographic evidence for reduced graft patency due to competitive flow in composite arterial T-grafts. J. Thorac. Cardiovasc. Surg. 133, 1220-1225. doi:10.1016/j.jtcvs.2006.07.060

Quint, C., Arief, M., Muto, A., Dardik, A., and Niklason, L. E. (2012). Allogeneic human tissue-engineered blood vessel. J. Vasc. Surg. 55, 790-798. doi:10.1016/j. jvs.2011.07.098

Ratcliffe, A. (2000). Tissue engineering of vascular grafts. Matrix Biol. 19, 353-357. doi:10.1016/S0945-053X(00)00080-9

Roh, J. D., Nelson, G. N., Brennan, M. P., Mirensky, T. L., Yi, T., Hazlett, T. F., et al. (2008). Small-diameter biodegradable scaffolds for functional vascular tissue engineering in the mouse model. Biomaterials 29, 1454-1463. doi:10.1016/j.biomaterials.2007.11.041
Roh, J. D., Sawh-Martinez, R., Brennan, M. P., Jay, S. M., Devine, L., Rao, D. A., et al. (2010). Tissue-engineered vascular grafts transform into mature blood vessels via an inflammation-mediated process of vascular remodeling. Proc. Natl. Acad. Sci. U.S.A. 107, 4669-4674. doi:10.1073/pnas.0911465107

Sabik, J. F. III, Lytle, B. W., Blackstone, E. H., Houghtaling, P. L., and Cosgrove, D. M. (2005). Comparison of saphenous vein and internal thoracic artery graft patency by coronary system. Ann. Thorac. Surg. 79, 544-551. doi:10.1016/j.athoracsur.2004.07.047

Sasagawa, T., Shimizu, T., Sekiya, S., Haraguchi, Y., Yamato, M., Sawa, Y., et al. (2010). Design of prevascularized three-dimensional cell-dense tissues using a cell sheet stacking manipulation technology. Biomaterials 31, 1646-1654. doi:10.1016/j.biomaterials.2009.11.036

Sekine, H., Shimizu, T., Sakaguchi, K., Dobashi, I., Wada, M., Yamato, M., et al. (2013). In vitro fabrication of functional three-dimensional tissues with perfusable blood vessels. Nat. Commun. 4, 1399. doi:10.1038/ncomms2406

Sheridan, W. S., Duffy, G. P., and Murphy, B. P. (2013). Optimum parameters for freeze-drying decellularized arterial scaffolds. Tissue Eng. C 19, 981-990. doi:10.1089/ten.TEC.2012.0741

Shukla, N., and Jeremy, J. Y. (2012). Pathophysiology of saphenous vein graft failure: a brief overview of interventions. Curr. Opin. Pharmacol. 12, 114-120. doi:10.1016/j.coph.2012.01.001

Soletti, L., Nieponice, A., Hong, Y., Ye, S. H., Stankus, J. J., Wagner, W. R., et al. (2011). In vivo performance of a phospholipid-coated bioerodable elastomeric graft for small-diameter vascular applications. J. Biomed. Mater. Res. A 96A, 436-448. doi:10.1002/jbm.a.32997

Song, Y., Wennink, J. W. H., Kamphuis, M. M. J., Sterk, L. M. T., Vermes, I., Poot, A. A., et al. (2011). Dynamic culturing of smooth muscle cells in tubular poly(trimethylene carbonate) scaffolds for vascular tissue engineering. Tissue Eng. A 17, 381-387. doi:10.1089/ten.TEA.2009.0805

Srokowski, E. M., Blit, P. H., McClung, W. G., Brash, J. L., Santerre, J. P., and Woodhouse, K. A. (2011). Platelet adhesion and fibrinogen accretion on a family of elastin-like polypeptides. J. Biomater. Sci., Polym. Ed. 22, 41-57. doi:10.1163/092050609X12578498935594

Swartz, D. D., and Andreadis, S. T. (2013). Animal models for vascular tissue-engineering. Curr. Opin. Biotechnol. 24, 916-925. doi:10.1016/j.copbio. 2013.05.005

Takahashi, K., and Yamanaka, S. (2006). Induction of pluripotent stem cells from mouse embryonic and adult fibroblast cultures by defined factors. Cell 126, 663-676. doi:10.1016/j.cell.2006.07.024

Tatoulis, J., Buxton, B. F., and Fuller, J. A. (2004). Patencies of 2,127 arterial to coronary conduits over 15 years. Ann. Thorac. Surg. 77, 93-101. doi:10.1016/S00034975(03)01331-6

Tranbaugh, R. F., Dimitrova, K. R., Friedmann, P., Geller, C. M., Harris, L. J., Stelzer, P., et al. (2012). Coronary artery bypass grafting using the radial artery: clinical outcomes, patency, and need for reintervention. Circulation 126, S170-S175. doi:10.1161/CIRCULATIONAHA.111.083048

Verhamme, P., and Hoylaerts, M. F. (2006). The pivotal role of the endothelium in haemostasis and thrombosis. Acta Clin. Belg. 61, 213-219. doi:10.1179/acb. 2006.036

Vijayan, V., Shukla, N., Johnson, J. L., Gadsdon, P., Angelini, G. D., Smith, F. C. T., et al. (2004). Long-term reduction of medial and intimal thickening in porcine saphenous vein grafts with a polyglactin biodegradable external sheath. J. Vasc. Surg. 40, 1011-1019. doi:10.1016/j.jvs.2004.08.047

Wang, C., Cen, L., Yin, S., Liu, Q., Liu, W., Cao, Y., et al. (2010). A small diameter elastic blood vessel wall prepared under pulsatile conditions from polyglycolic acid mesh and smooth muscle cells differentiated from adiposederived stem cells. Biomaterials 31, 621-630. doi:10.1016/j.biomaterials.2009. 09.086

Wang, S., Gupta, A. S., Sagnella, S., Barendt, P. M., Kottke-Marchant, K., and Marchant, R. E. (2009). Biomimetic fluorocarbon surfactant polymers reduce platelet adhesion on PTFE/ePTFE surfaces. J. Biomater. Sci. Polym. Ed. 20, 619-635. doi:10.1163/156856209X426439

Wang, Z., Cui, Y., Wang, J., Yang, X., Wu, Y., Wang, K., et al. (2014). The effect of thick fibers and large pores of electrospun poly( $\varepsilon$-caprolactone) vascular grafts on macrophage polarization and arterial regeneration. Biomaterials 35, 5700-5710. doi:10.1016/j.biomaterials.2014.03.078

Webb, C. M., Moat, N. E., Chong, C. F., and Collins, P. (2010). Vascular reactivity and flow characteristics of radial artery and long saphenous vein coronary 
bypass grafts: a 5-year follow-up. Circulation 122, 861-867. doi:10.1161/ CIRCULATIONAHA.109.887000

Weber, B., Emmert, M. Y., Schoenauer, R., Brokopp, C., Baumgartner, L., and Hoerstrup, S. P. (2011). Tissue engineering on matrix: future of autologous tissue replacement. Semin. Immunopathol. 33, 307-315. doi:10.1007/s00281011-0258-8

Weinberg, C. B., and Bell, E. (1986). A blood vessel model constructed from collagen and cultured vascular cells. Science 231, 397-400. doi:10.1126/science.2934816

Williams, S. K., Kleinert, L. B., and Patula-Steinbrenner, V. (2011). Accelerated neovascularization and endothelialization of vascular grafts promoted by covalently bound laminin type 1. J. Biomed. Mater. Res. A 99A, 67-73. doi:10.1002/jbm.a. 33138

Wilshaw, S. P., Rooney, P., Berry, H., Kearney, J. N., Homer-Vanniasinkam, S., Fisher, J., et al. (2012). Development and characterization of acellular allogeneic arterial matrices. Tissue Eng. A 18, 471-483. doi:10.1089/ten.TEA.2011.0287

Wong, G., Li, J., Hendricks, G., Eslami, M. H., Rohrer, M. J., and Cutler, B. S. (2008). Inhibition of experimental neointimal hyperplasia by recombinant human thrombomodulin coated ePTFE stent grafts. J. Vasc. Surg. 47, 608-615. doi:10.1016/j.jvs.2007.11.025

Woodhouse, K. A., Klement, P., Chen, V., Gorbet, M. B., Keeley, F. W., Stahl, R., et al. (2004). Investigation of recombinant human elastin polypeptides as nonthrombogenic coatings. Biomaterials 25, 4543-4553. doi:10.1016/j.biomaterials. 2003.11.043

Wu, W., Allen, R., Gao, J., and Wang, Y. (2011). Artificial niche combining elastomeric substrate and platelets guides vascular differentiation of bone marrow mononuclear cells. Tissue Eng. A 17, 1979-1992. doi:10.1089/ten.TEA. 2010.0550

Wu, W., Allen, R. A., and Wang, Y. (2012). Fast-degrading elastomer enables rapid remodeling of a cell-free synthetic graft into a neoartery. Nature Med. 18, 1148-1153. doi:10.1038/nm.2821

Xiong, Y., Chan, W. Y., Chua, A. W. C., Feng, J., Gopal, P., Ong, Y. S., et al. (2013). Decellularized porcine saphenous artery for small-diameter tissue-engineered conduit graft. Artif. Organs 37, E74-E87. doi:10.1111/aor.12014

Yagi, T., Sato, M., Nakazawa, Y., Tanaka, K., Sata, M., Itoh, K., et al. (2011). Preparation of double-raschel knitted silk vascular grafts and evaluation of short-term function in a rat abdominal aorta. J. Artif. Organs 14, 89-99. doi:10.1007/s10047-011-0554-z

Yoneyama, T., Ishihara, K., Nakabayashi, N., Ito, M., and Mishima, Y. (1998). Short-term in vivo evaluation of small-diameter vascular prosthesis composed of segmented poly(etherurethane)/2-methacryloyloxyethyl phosphorylcholine polymer blend. J. Biomed. Mater. Res. 43, 15-20. doi:10.1002/(SICI)10974636(199821)43:13.0.CO;2-P
Zaidi, T. N., McIntire, L. V., Farrell, D. H., and Thiagarajan, P. (1996). Adhesion of platelets to surface-bound fibrinogen under flow. Blood 88, 2967-2972.

Zhang, X., Wang, X., Keshav, V., Johanas, J. T., Leisk, G. G., and Kaplan, D. L. (2009). Dynamic culture conditions to generate silk-based tissue-engineered vascular grafts. Biomaterials 30, 3213-3223. doi:10.1016/j.biomaterials.2009.02.002

Zhao, Y., Zhang, S., Zhou, J., Wang, J., Zhen, M., Liu, Y., et al. (2010). The development of a tissue-engineered artery using decellularized scaffold and autologous ovine mesenchymal stem cells. Biomaterials 31, 296-307. doi:10.1016/j. biomaterials.2009.09.049

Zheng, W., Wang, Z., Song, L., Zhao, Q., Zhang, J., Li, D., et al. (2012). Endothelialization and patency of RGD-functionalized vascular grafts in a rabbit carotid artery model. Biomaterials 33, 2880-2891. doi:10.1016/j.biomaterials.2011.12.047

Zhou, M., Liu, Z., Liu, C., Jiang, X., Wei, Z., Qiao, W., et al. (2012). Tissue engineering of small-diameter vascular grafts by endothelial progenitor cells seeding heparin-coated decellularized scaffolds. J. Biomed. Mater. Res. B 100B, 111-120. doi:10.1002/jbm.b.31928

Zhu, M., Wang, K., Mei, J., Li, C., Zhang, J., Zheng, W., et al. (2014). Fabrication of highly interconnected porous silk fibroin scaffolds for potential use as vascular grafts. Acta Biomater. 10, 2014-2023. doi:10.1016/j.actbio.2014.01.022

Zilla, P., Human, P., Wolf, M., Lichtenberg, W., Rafiee, N., Bezuidenhout, D., et al. (2008). Constrictive external nitinol meshes inhibit vein graft intimal hyperplasia in nonhuman primates. J. Thorac. Cardiovasc. Surg. 136, 717-725. doi:10.1016/j.jtcvs.2008.02.068

Zilla, P., Moodley, L., Wolf, M. F., Bezuidenhout, D., Sirry, M. S., Rafiee, N. R., et al. (2011). Knitted nitinol represents a new generation of constrictive external vein graft meshes. J. Vasc. Surg. 54, 1439-1450. doi:10.1016/j.jvs.2011.05.023

Conflict of Interest Statement: The authors declare that the research was conducted in the absence of any commercial or financial relationships that could be construed as a potential conflict of interest.

Received: 05 April 2014; accepted: 26 May 2014; published online: 10 June 2014. Citation: Knight DK, Gillies ER and Mequanint K (2014) Vascular grafting strategies in coronary intervention. Front. Mater. 1:4. doi: 10.3389/fmats.2014.00004

This article was submitted to Biomaterials, a section of the journal Frontiers in Materials.

Copyright (C) 2014 Knight, Gillies and Mequanint. This is an open-access article distributed under the terms of the Creative Commons Attribution License (CC BY). The use, distribution or reproduction in other forums is permitted, provided the original author(s) or licensor are credited and that the original publication in this journal is cited, in accordance with accepted academic practice. No use, distribution or reproduction is permitted which does not comply with these terms. 